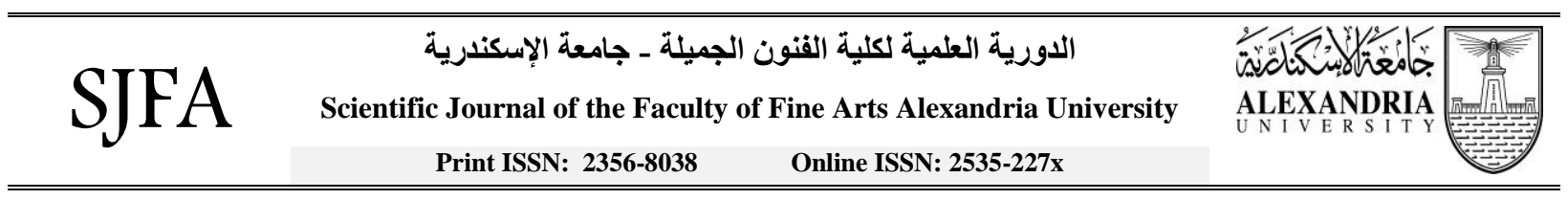

\title{
القيمة الجمالية للأسقف المعاصرة
}

\author{
جميله سليمان جو هر سالم'
}

تستقبل الدورية العلمية لكلية الفنون الجميلة - جامعة الاسكندرية الورقات البحثية/ الأبحاث العلمية. حيث أنها تقوم بإعدادها

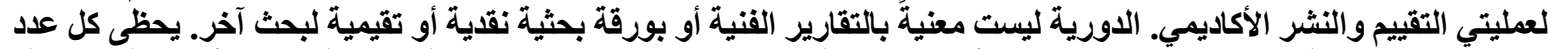

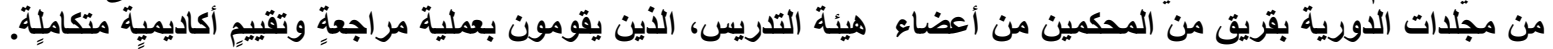

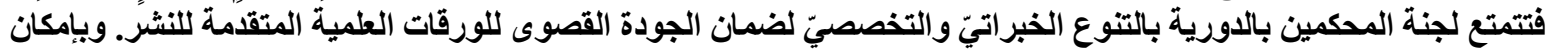

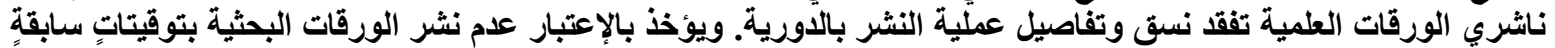

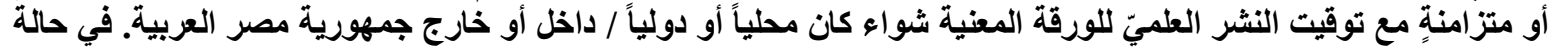

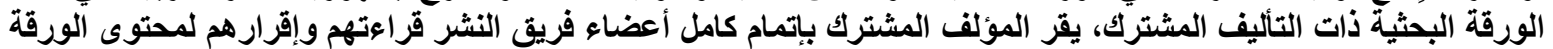

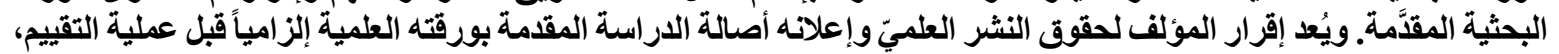

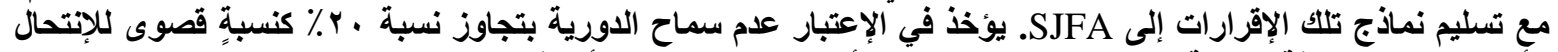

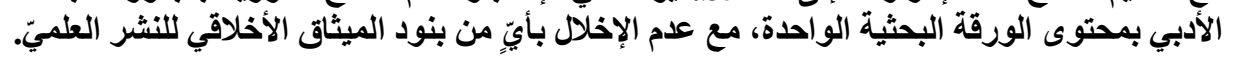

الكلمات الدالة: النسق، الدقدة، الخطوط، العناوبن، الأشكال، المعادلات.

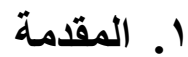

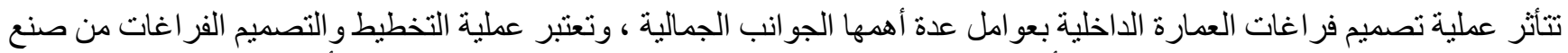

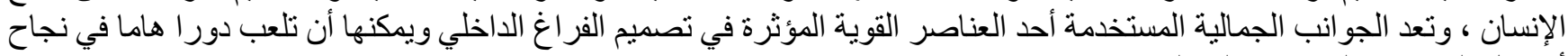

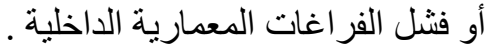

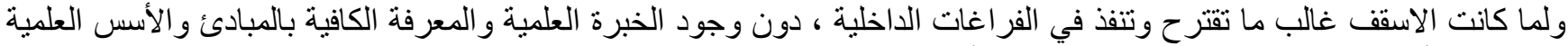

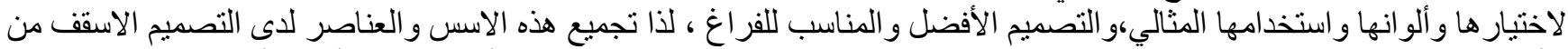

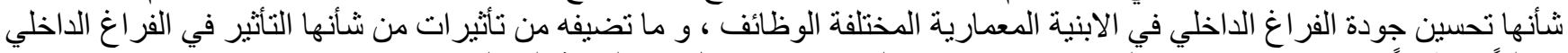

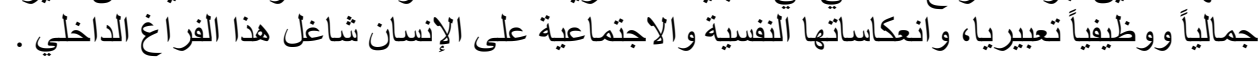

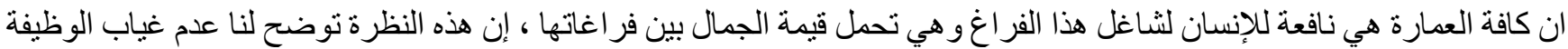

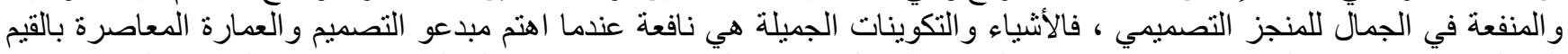

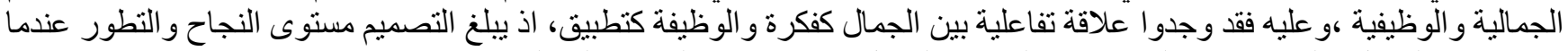

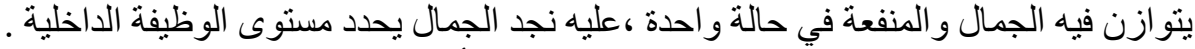

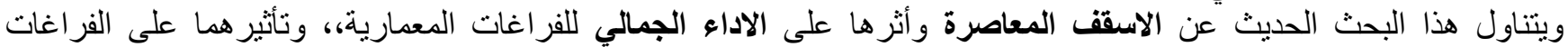

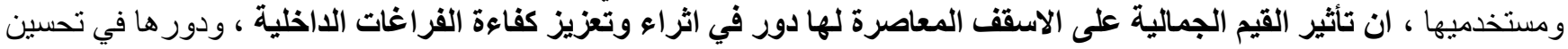

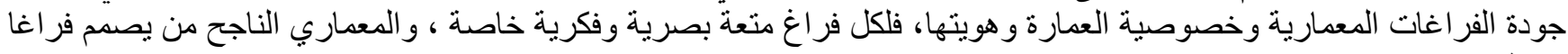
يسيطر ويحوي احاسيس الافر اد. 


\section{SJFA Scientific Journal of the Faculty of Fine Arts Alexandria University}

يمثل السقف جز ءا لا يتجزأ من العملية التصميمية للفراغات المعمارية ينظر أصحاب المنازل إلى الجدران والأرضيات بدلاً من النظر

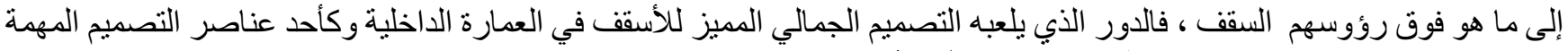

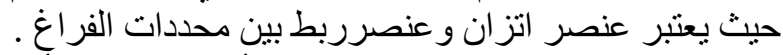

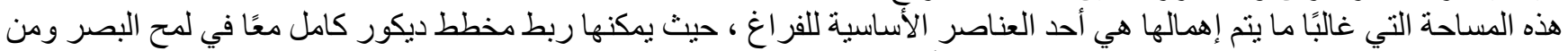

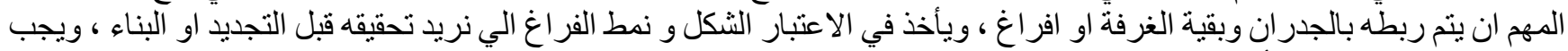

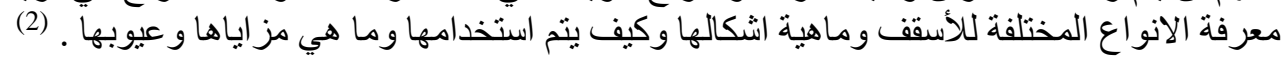

ب- بطة البحث

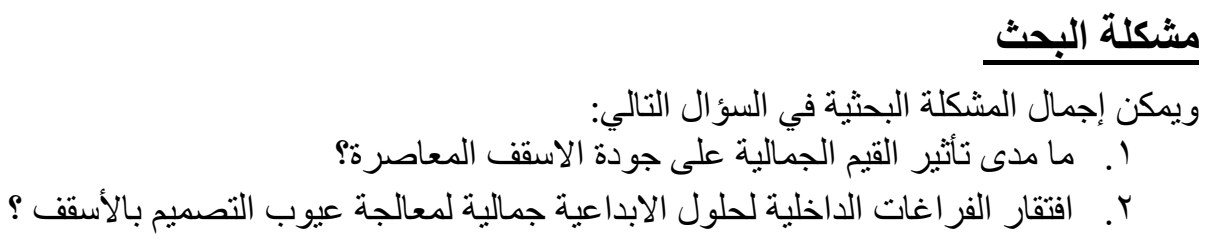

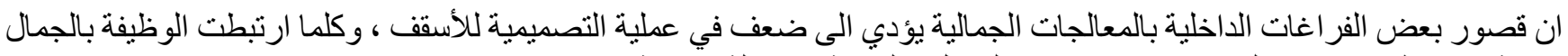
مما اثر في تطوير مبادئ التصميم ويتو ازن فيه الجمال و المنفعة في حالة ابداعية واحدة . لئل

أهمية البحث

• تنبع اهمية هذا البحث في دراسة مدى تأثير القيم الجمالية للأسقف المعاصرة في العمارة الإخلية و الفر اغات المختلف الوظيفية

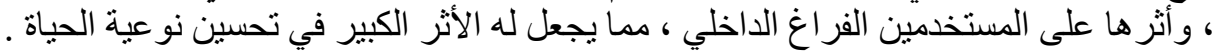

هدف البحث

1. تسليط الضوء على أهمية الدراسـة الجوانب الجمالية وأثر ها في عمليـة تصميم الاسقف المعاصرة بما يتناسب مع مستخدميها

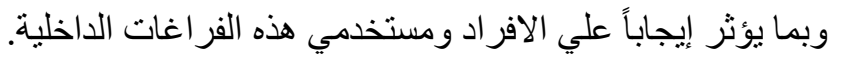

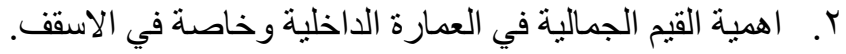

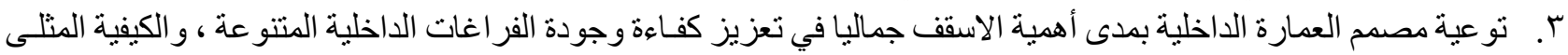
في توظيف مو اد الانثاء المعاصرة في خدمة الاسقف الداخلية والطابع المعماري لها.

فرضية البحث

ا . . يطرح البحث فرضية اساسية ان القيم الجمالية لها القدرة لحل العديدة من المشاكل التصميمية في العمارة الداخلية .

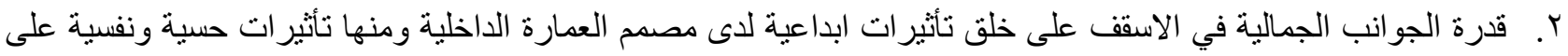

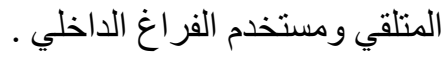

(2) https://ar.designlvl.eu/اختيار -انو اع_الاسقف_هو -قرار-تصميم- مهم 


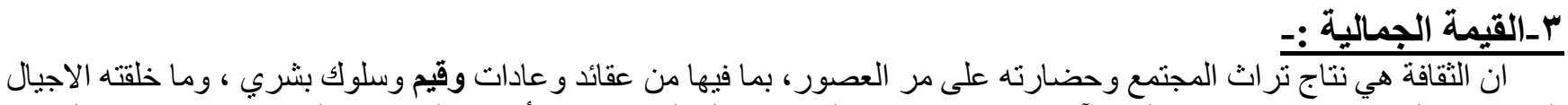

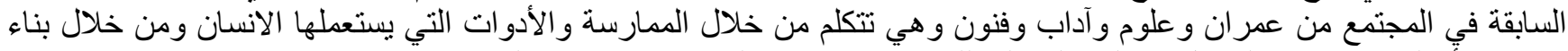

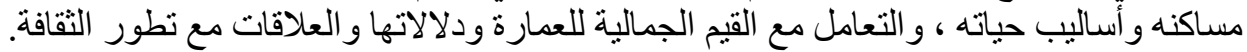

تعتبر القعريف عنصر القيم :-

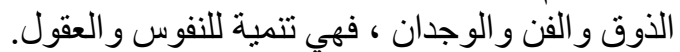

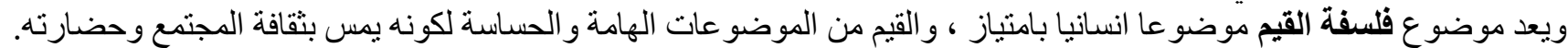

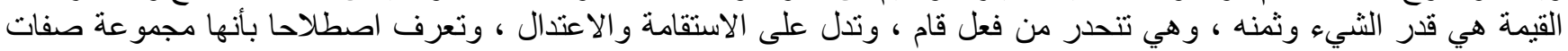

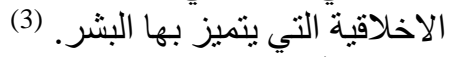

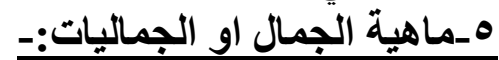

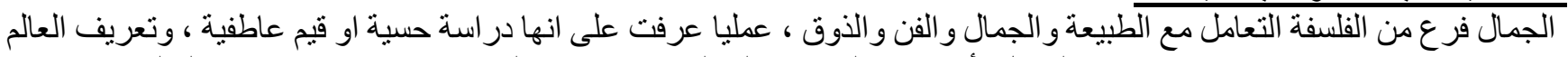

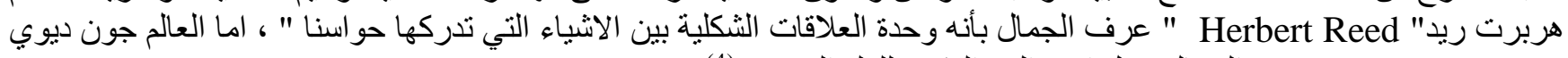

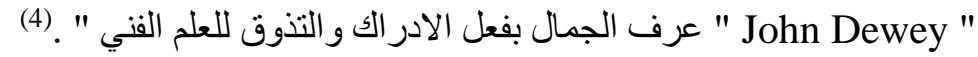

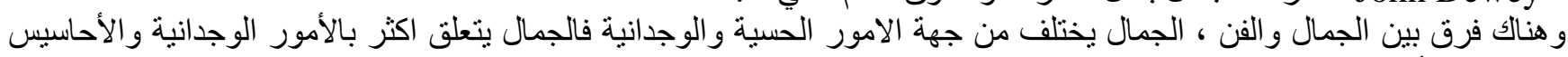

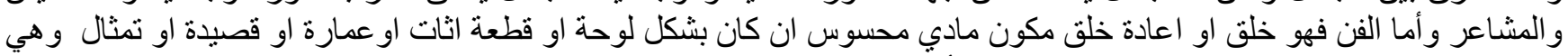

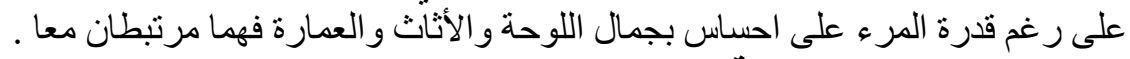

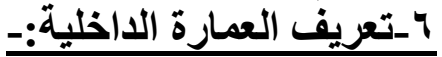

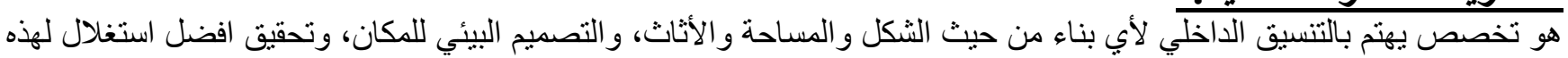

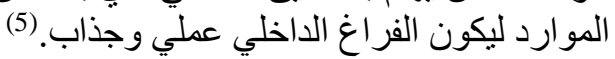

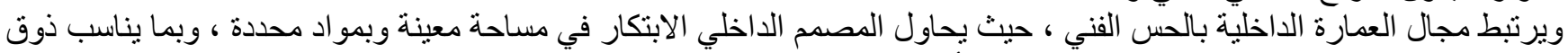

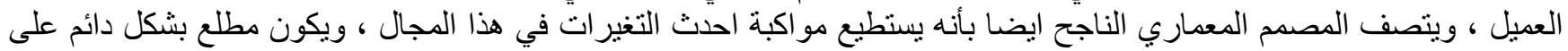

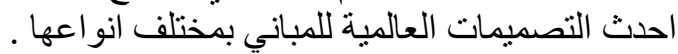

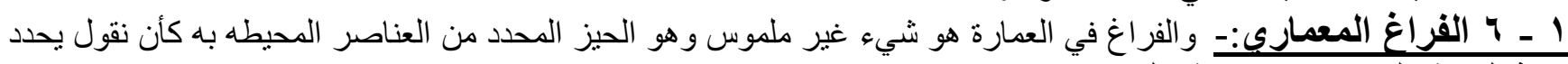

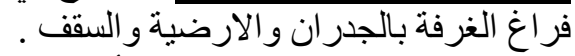

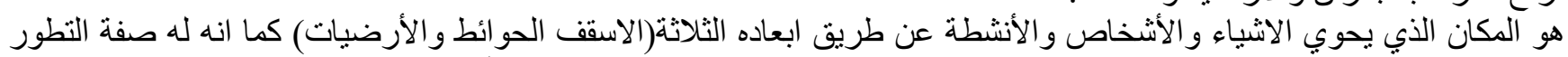

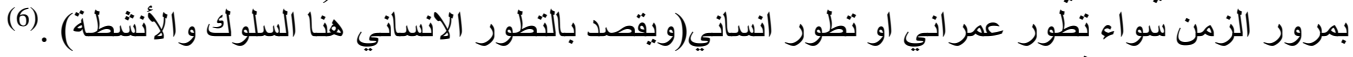

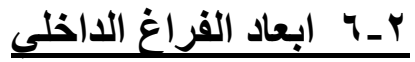

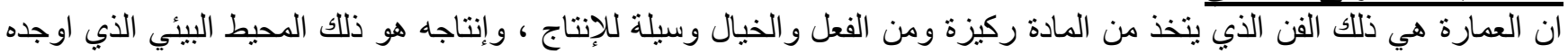

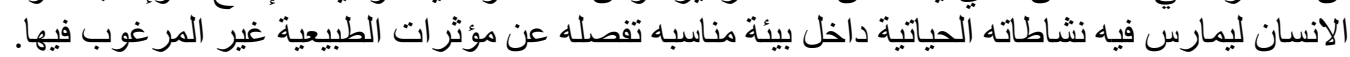

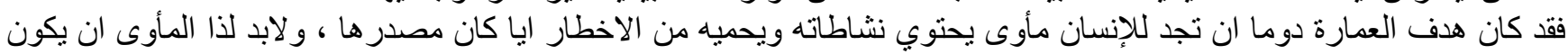

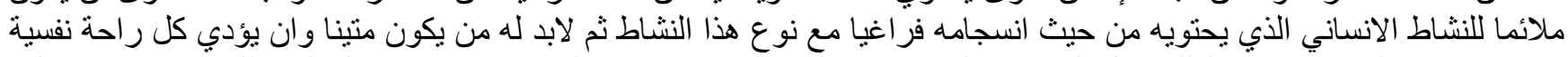

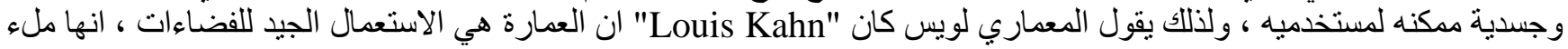

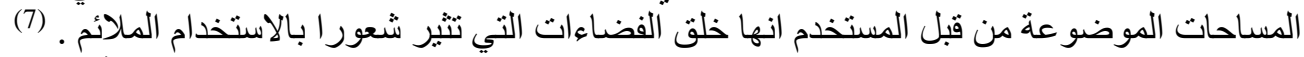

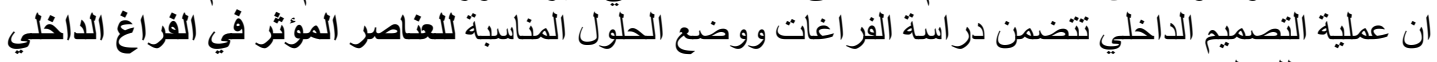

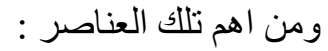

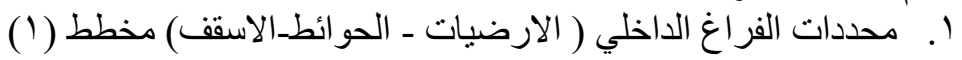
r r الخامات ومواد التشطيب

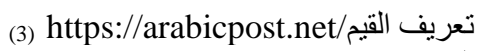
(4)https://ar.wikipedia.org/wiki/ تعريف فلسفة الجمارة//2) (5) https://oktamam.com/العمارة-و العمارة الداخلية//2

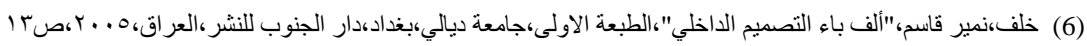
(7) Ashihar.Yoshinobu-'Exterior Design In Architecture'-Van Nostrand Reinhold.NEW York..1981,P(14) 


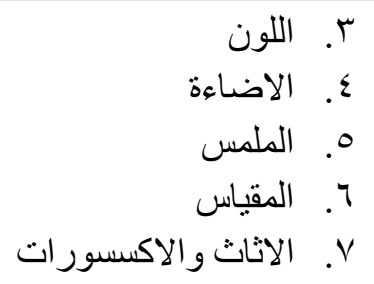

يقوم المصمم الداخلي باختيار المناسب لجميع هذه العناصر في الفراغ إن ، وتتنوع الخامات و المو اد التى يمكن للمصمم الداخلي استخدامها

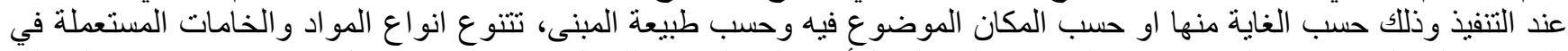

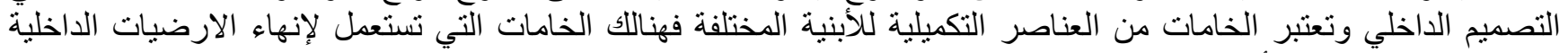

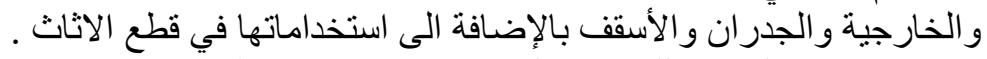

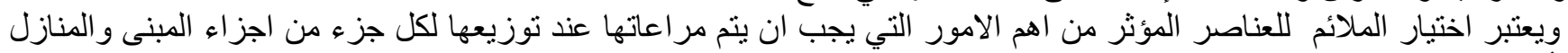

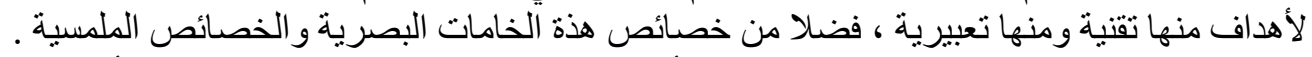

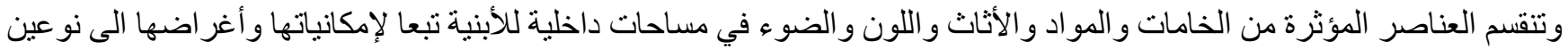
رئيسيين الخامات المحلية و الخامات الحديثة ، وكما تعتمد على كونها طنئ ولثيعية او مصنعة.

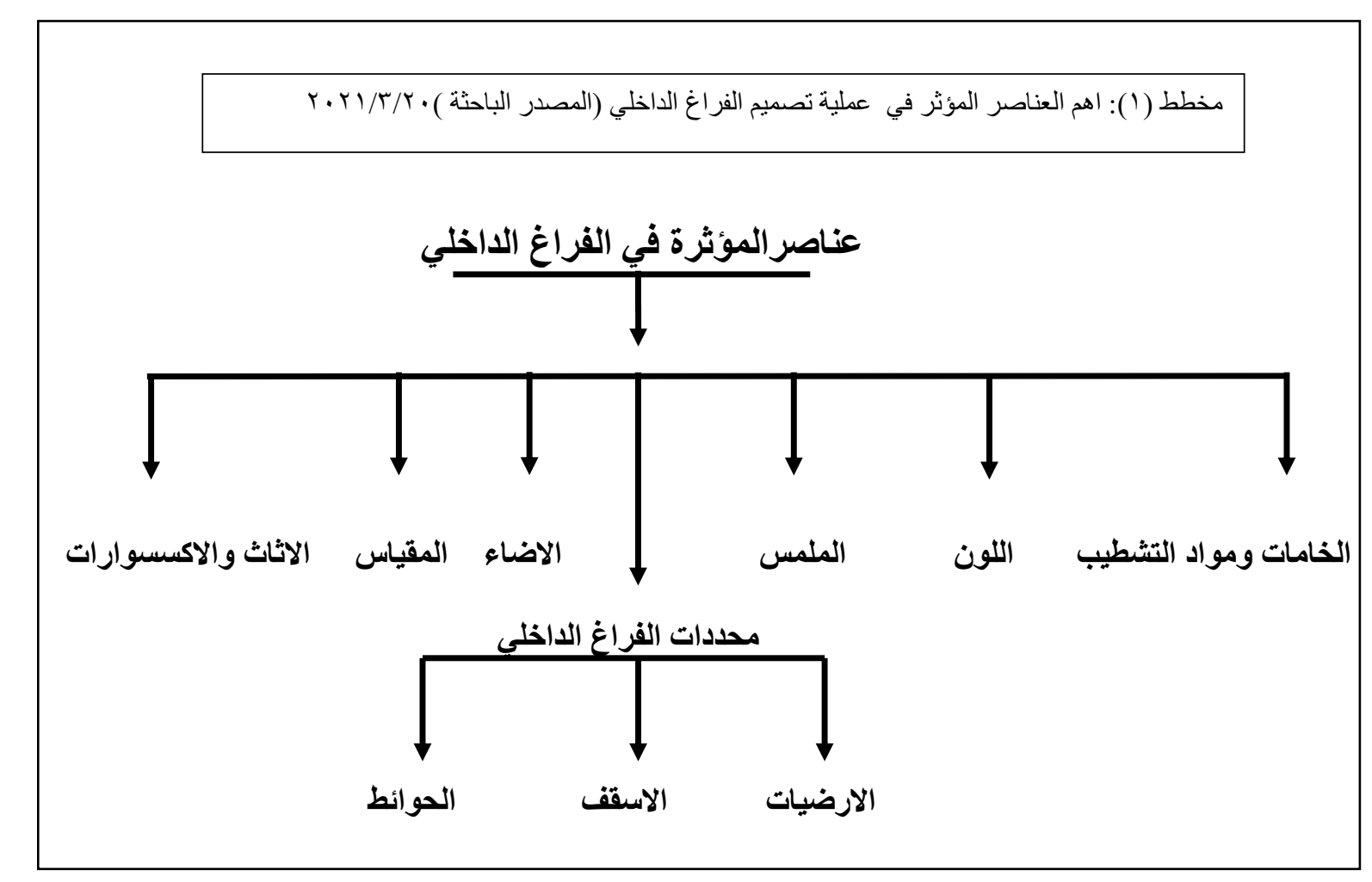

ونلاحظ ان الفر اغ الداخلي هو الفضاء المعد لنشاط الانساني ولذا يجب تنظيم العلاقات المعمارية لهذا الفر اغ من الحوائط والأسقف

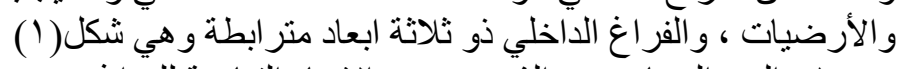

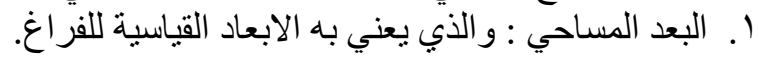

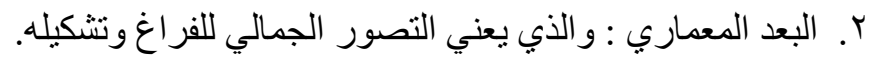

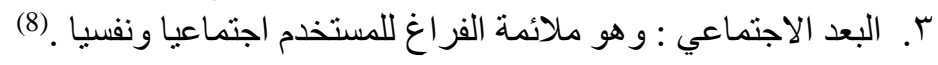


G. Salem, The Aesthetic Value of Contemporary Ceilings; Vol. 9, R. 2021, Issue No. 1.

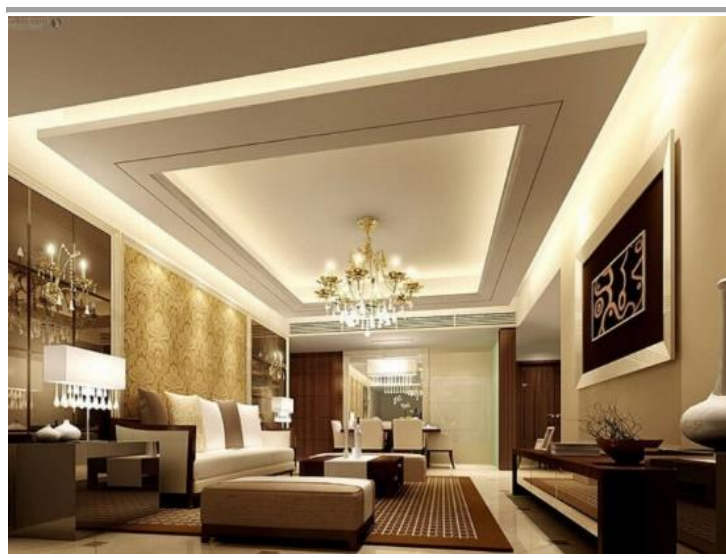

شكل ( ) ابعاد الفراغ الداخلي

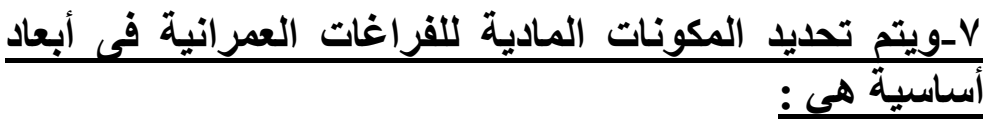

7-1

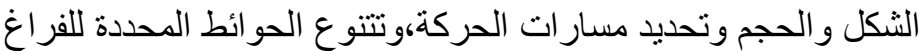

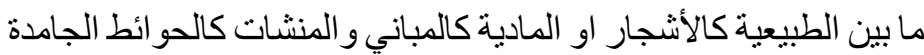

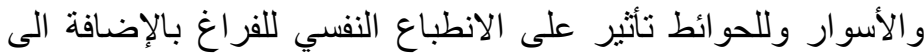
توجيه الحركة و الخصوصية والطية 7-2

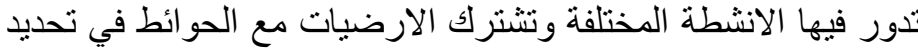

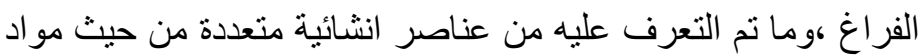

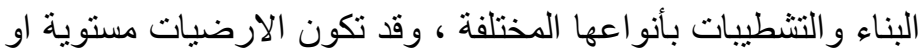

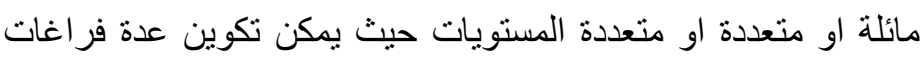
داخل الفر اغ الو احد عن طريق تعدد المستويات وتعدد النو عيات من ارضيات خشنة او ناعمة طبيعية او صناعية مستمرة ام متقطعة

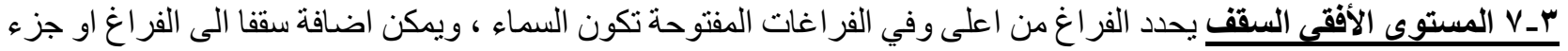

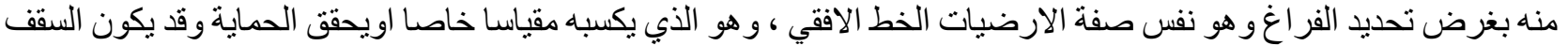

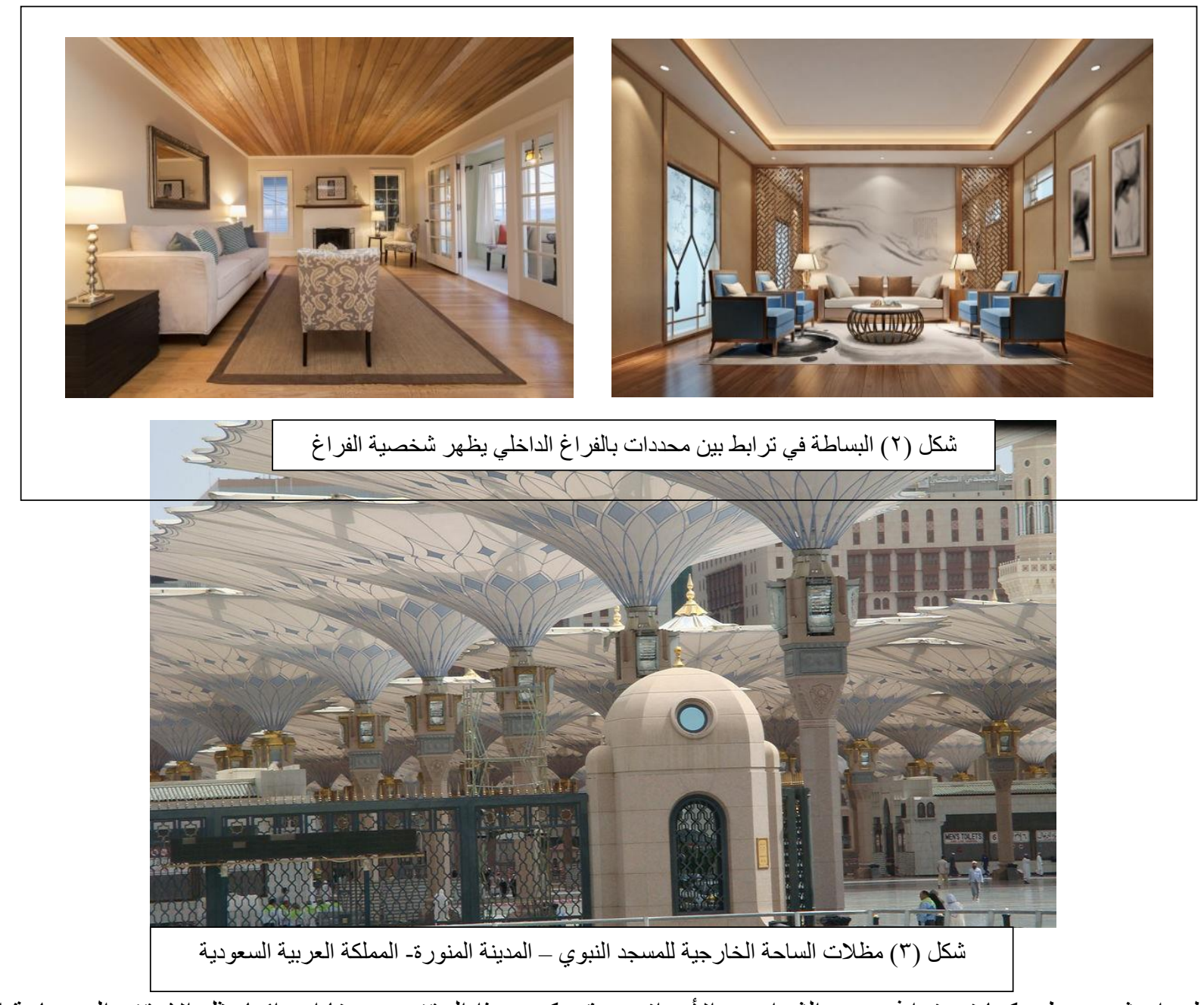

مغطى او شبه مغطى كما في فر اغ بعض الثو ارع و الأسواق ، وقد يكون هذا السقف مصمتا او دائما مثل الاسقف الخرسانية او 


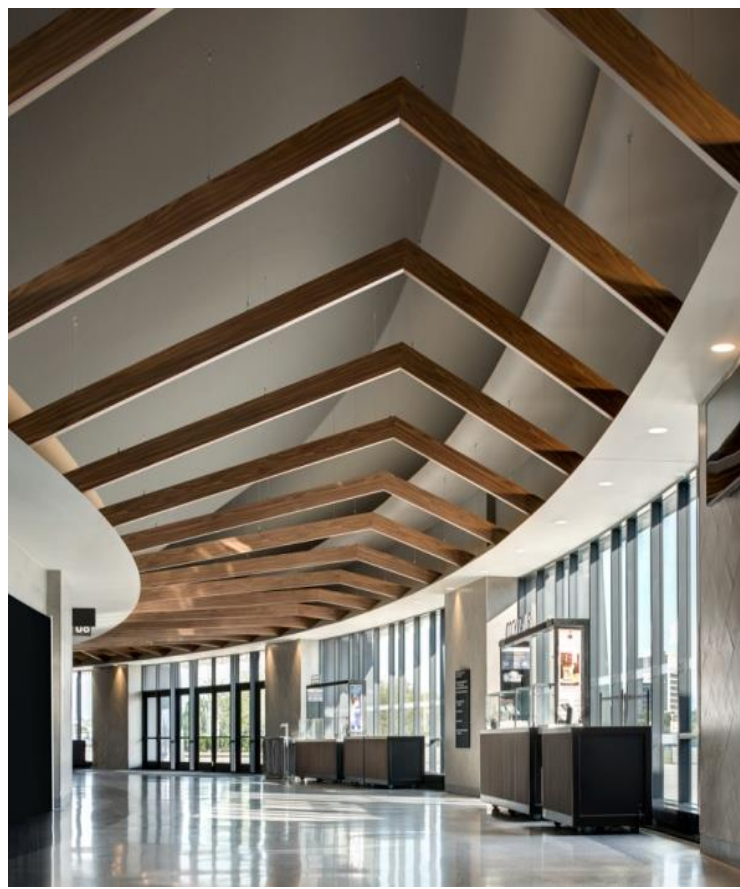

شكل (ع ) الاسقف الداخلية اذا تم توظيفها بالثكل

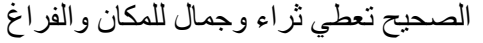

الحديدية او خفيفا مثل النباتات والأقمشة و البلاستيك تقوم بدور جمالي

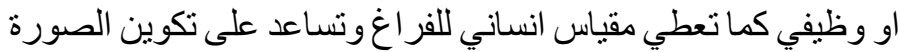

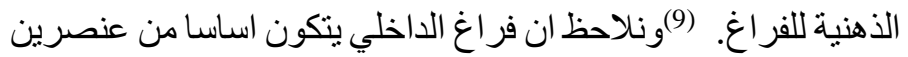

1- البيئة المادية :- التي تعطي للفر اغ الداخلي شكله وطابعة الخاص.

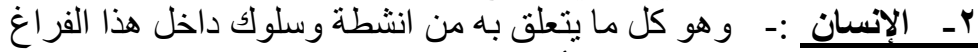

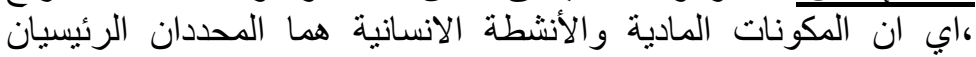

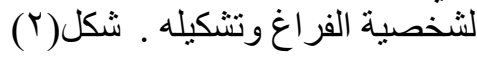

\section{1ـ - تعريف الاسقف الداخلية}

يعتبر الأسقف هو خط السماء داخل الفراغ الداخلي وهو الأله

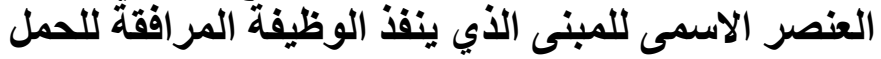

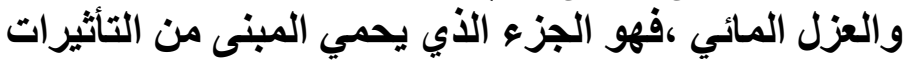

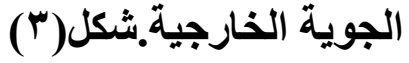

فان الاسقف الاخلية واحد من العناصر التي اذا تم توظيفها

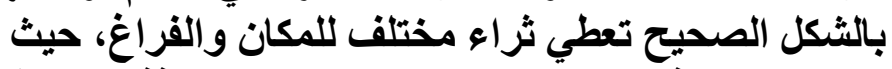
انها الاساس في توزيع الاضاءة والفتحات النوافت وافت وحتى قطع

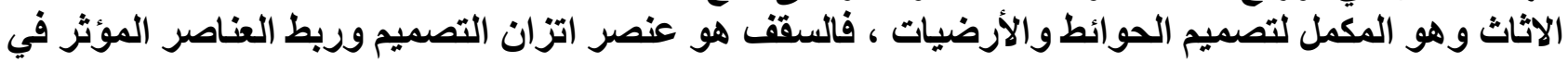

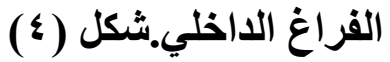

فالأسقف أحد العناصر الاساسية في العمارة الداخلية، حيث يعد الرابط العلوي لأسطح المباني والمنازل

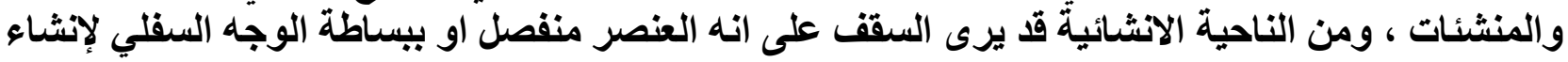

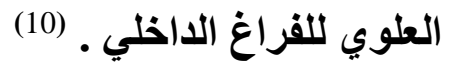

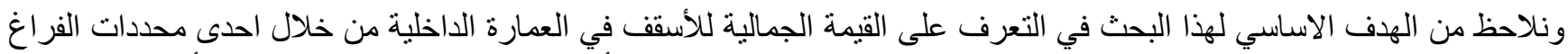

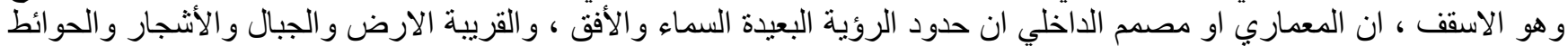

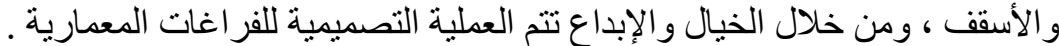

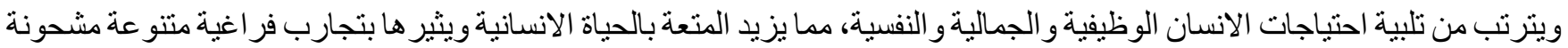

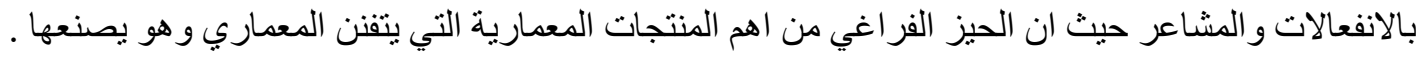

\section{9ـ القيم الجمالية للأسقف في بعض الطرز القديمة:-}

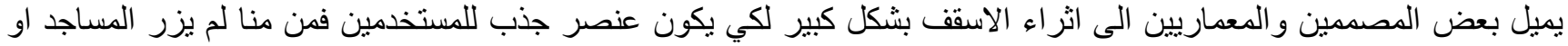

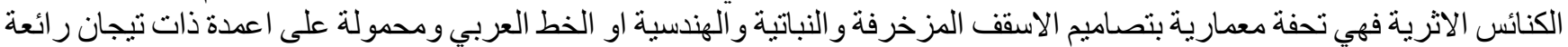

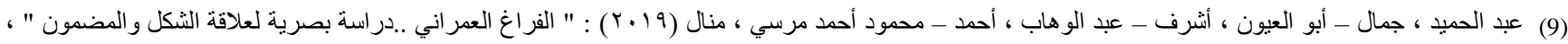
Journal of Advanced Engineering Trends (JAET), Vol. 38, No. 2. July 2019

(10)https://www.aaciaegypt.com/wp-content/uploads/2018/04/اليات_التشكيل-في_التصميم-الداخلي 
G. Salem, The Aesthetic Value of Contemporary Ceilings; Vol. 9, R. 2021, Issue No. 1.

وازدهرت طرز ديكور ات الاسقف منذ العصر الذهبي للفن الاسباني والايطالي ، حيث كان الرسم والنقش على اسقف الكنائس والأديرة

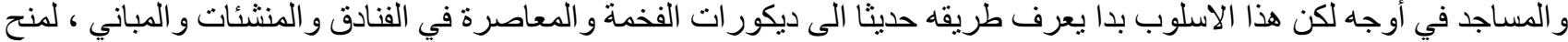
المكان عر اقة وفخامة و الى جانب البساطة الجميلة لذللك اصبحت الاسقف من اهم مفردات التصميم الداخلي .

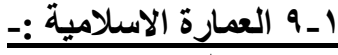

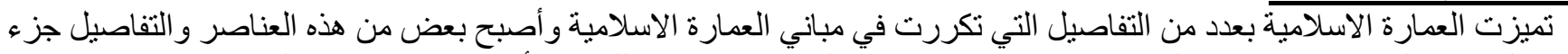

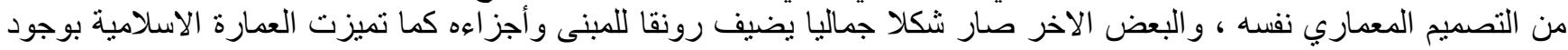

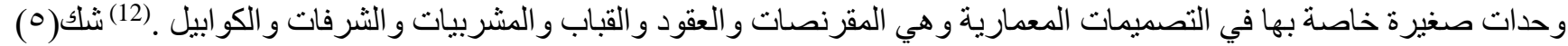

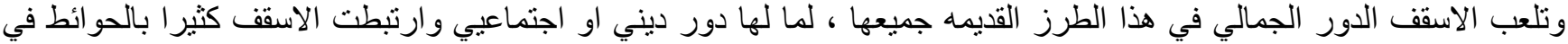

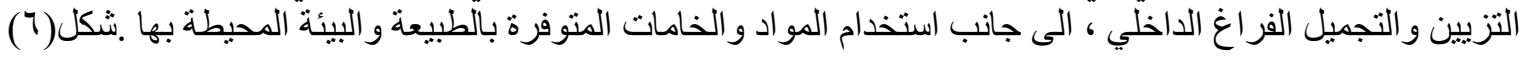
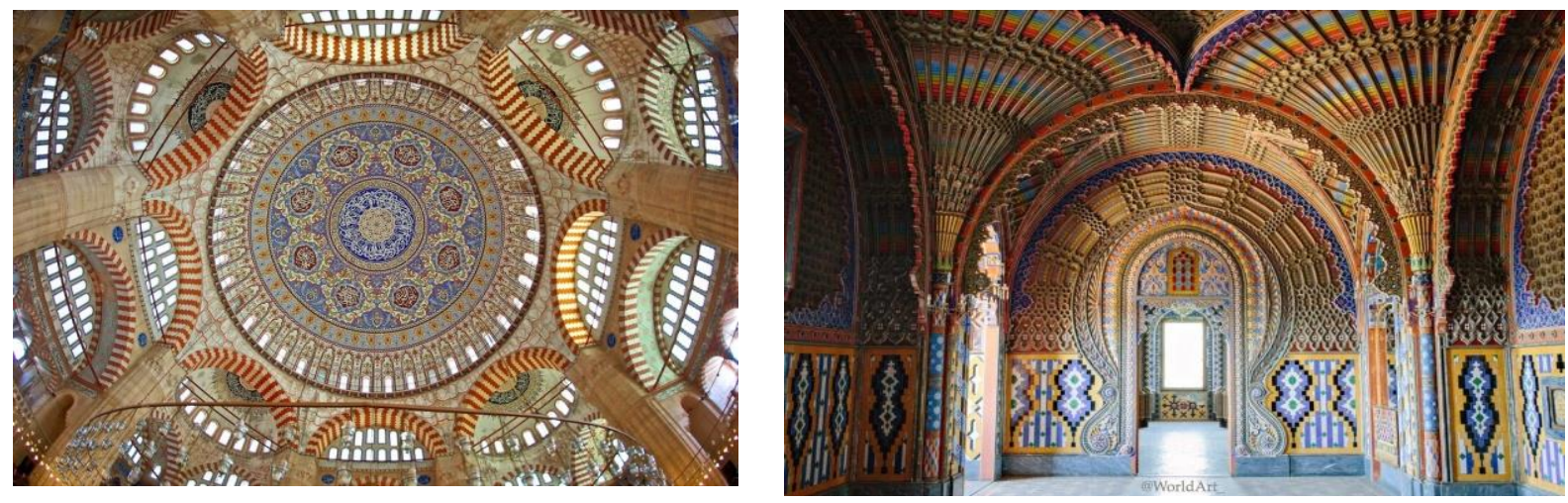

شكل (0) تلعب الاسقف الدور الجمالي الطرز القديمه جميعها ، ولما لها دور ديني او اجتماعي.

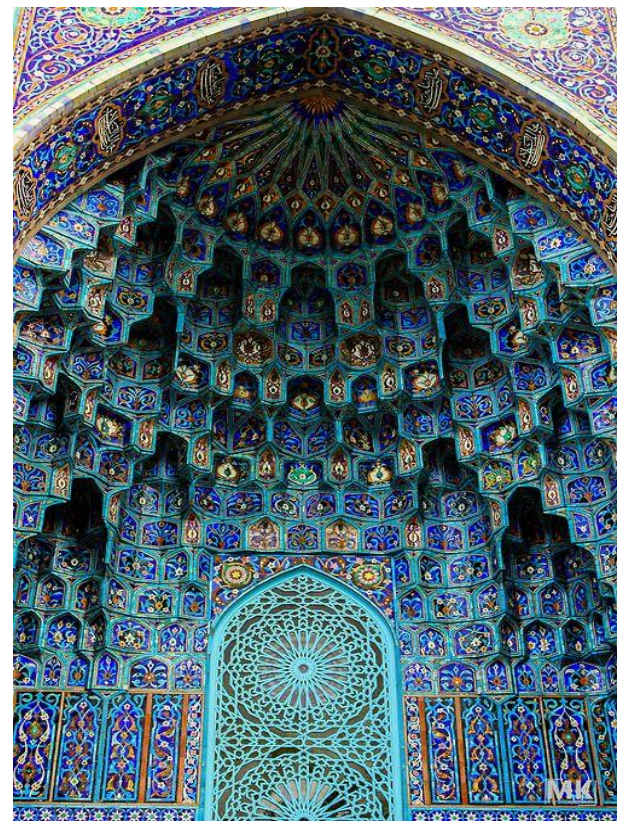

شكل (T) جمالية الاسقف القديمة امتدادها

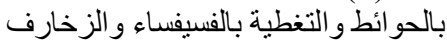

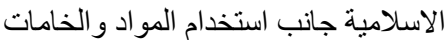

المنوفرة بالطبيعة و البيئة المحيطة بهان المواد الخهات

/الأسقف_المعلقة_أصبحت_من_مفردات_التصميم_الداخلي/11)https://www.algamal.net/8606

(12) https://e3arabi.com/الهندسة/تاريخ=العمارة/عناصر -الاسلامية/ 


\section{SJFA \\ Scientific Journal of the Faculty of Fine Arts Alexandria University}

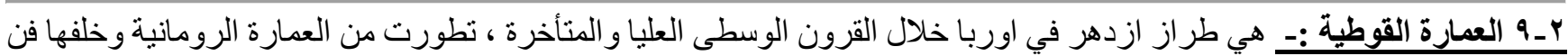

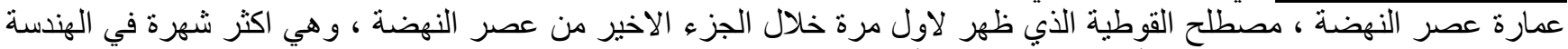

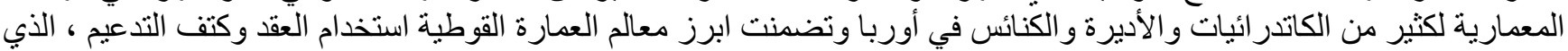

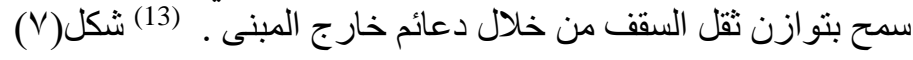
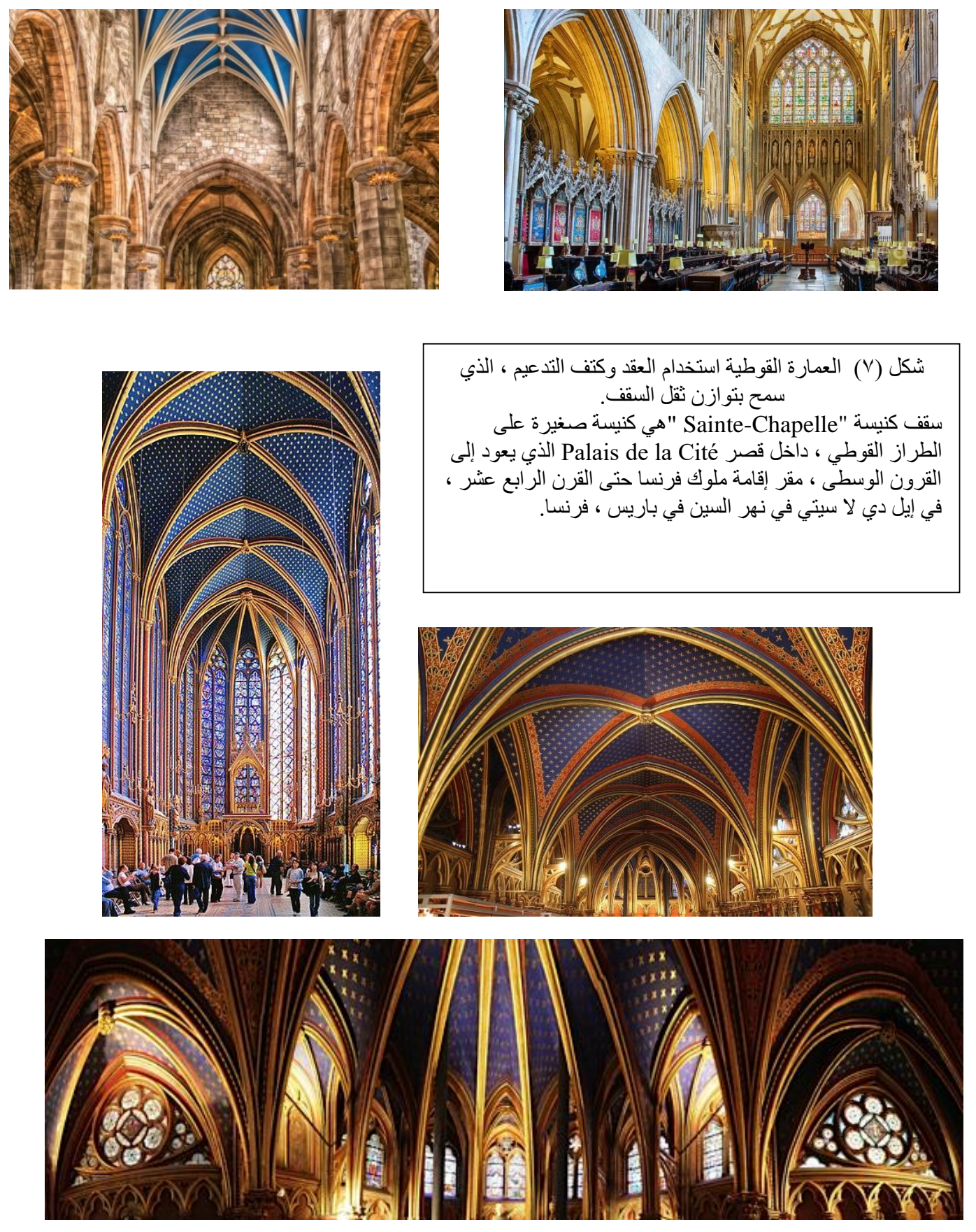

(13)https://ar.wikipedia.org/wiki/عمارة-قوطية 
G. Salem, The Aesthetic Value of Contemporary Ceilings; Vol. 9, R. 2021, Issue No. 1.

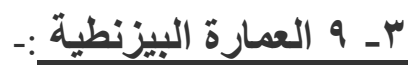

تعرف على انها من الفنون المعمارية في عصر فجر المئه الميحية ، و الذي تركته الحضارة البيزنطية القديمة ، وظهر في الامبر اطورية

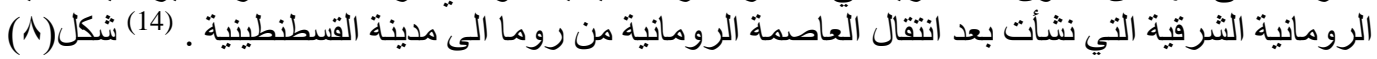
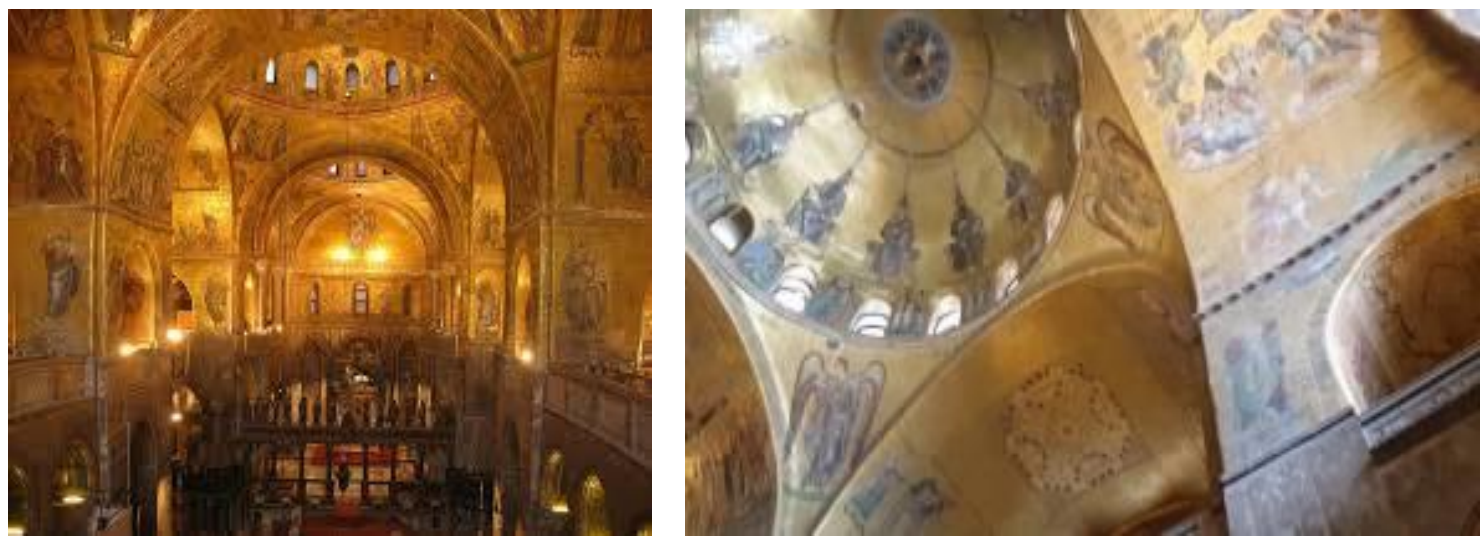

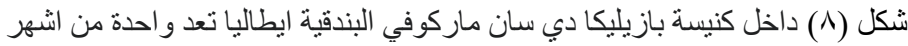

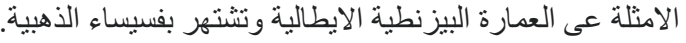

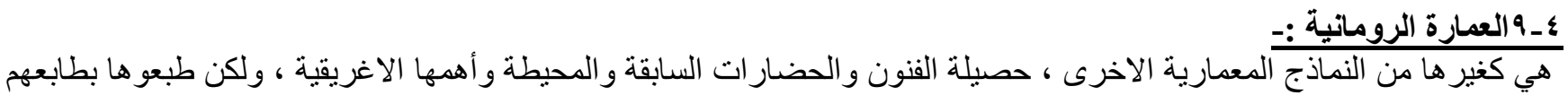

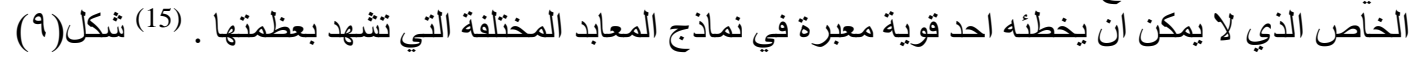
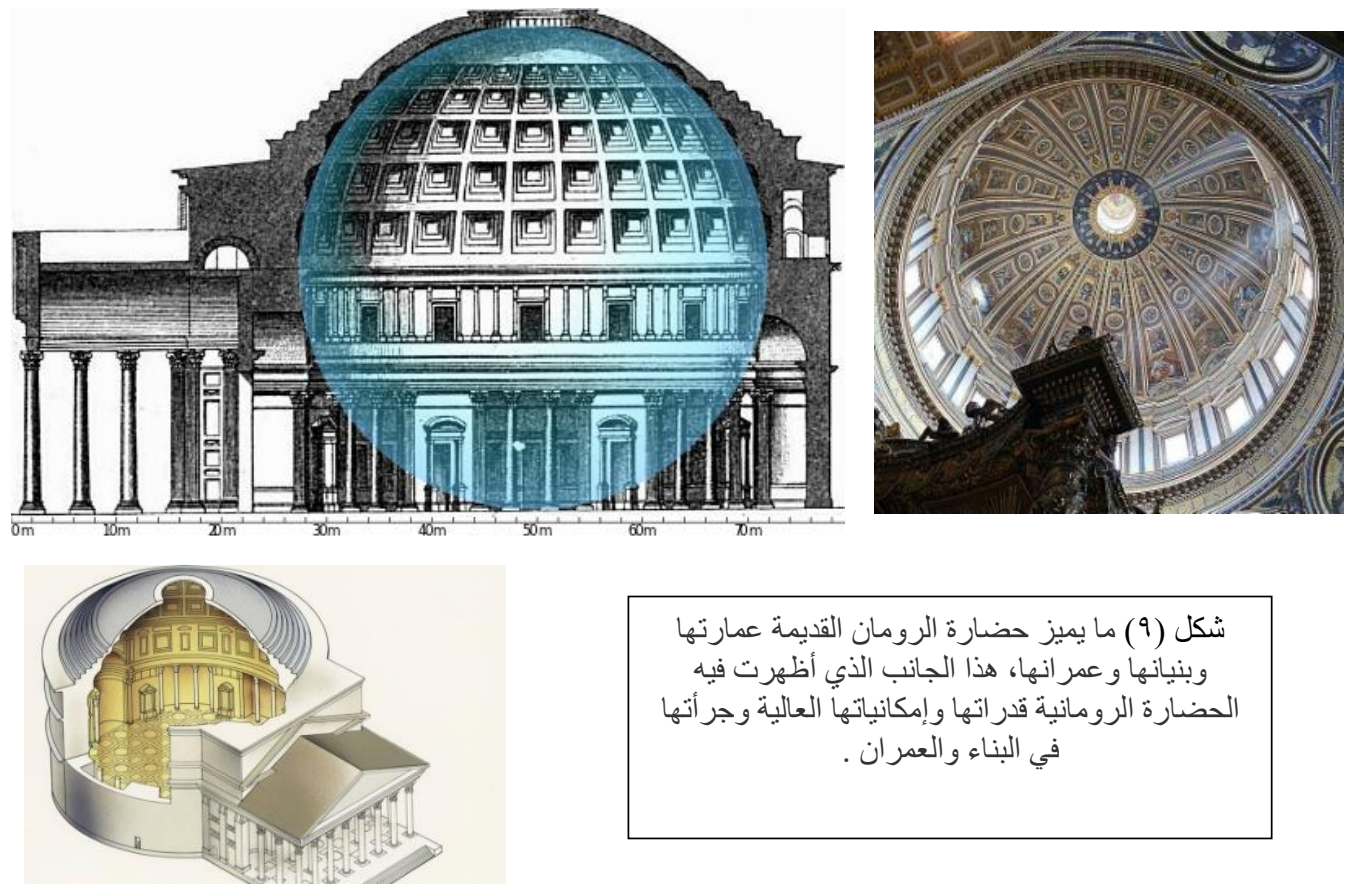

$$
\begin{aligned}
& \text { شكل (9) ما يميز حضارة الرومان القديمة عمارتها }
\end{aligned}
$$

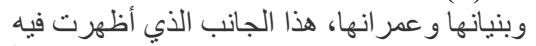

$$
\begin{aligned}
& \text { الحضارة الرومانبة قدر اتها و إمكانياتهاً العالية وجر أنهان التها } \\
& \text { في البناء و العمران انهان }
\end{aligned}
$$

(14) / https://ar.wikipedia.org/wiki العمارة البيزنطية//20)

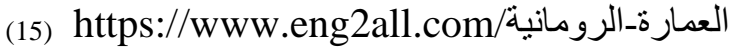




\section{SJFA}

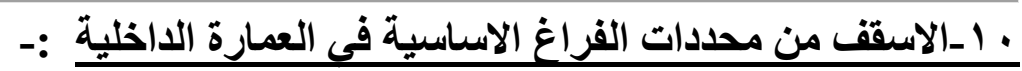

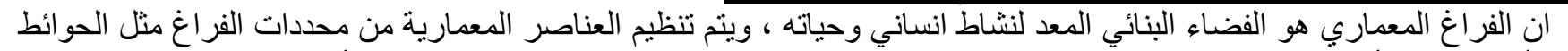

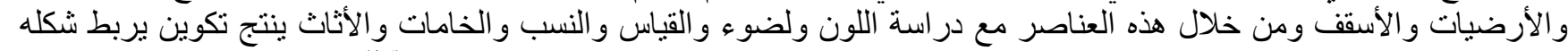

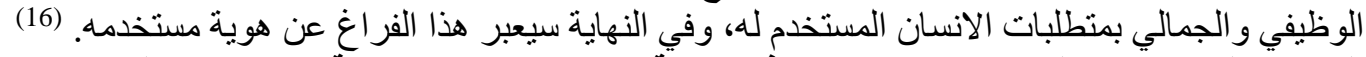

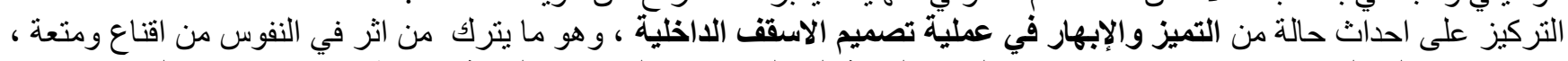

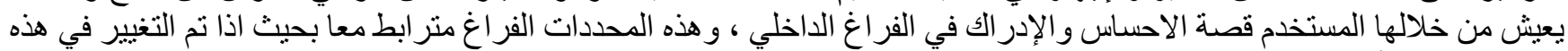

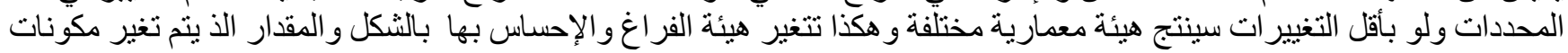

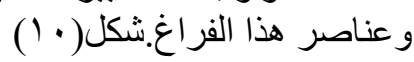
الأسقف هو العنصر الأساسي لحماية الابنية من الداخل لجميع المنشئات، ومع التطور الدائم في هندسة العمارة الداخلية ، ودخول العديد

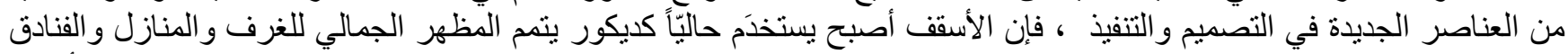

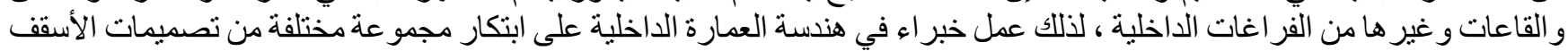

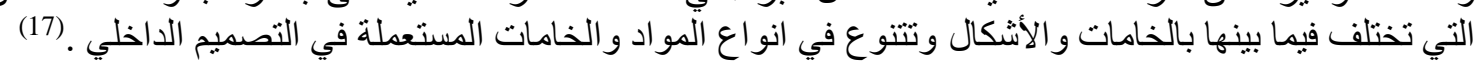

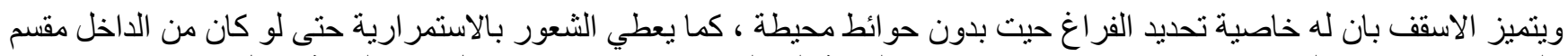

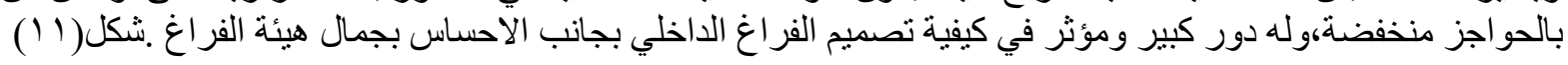

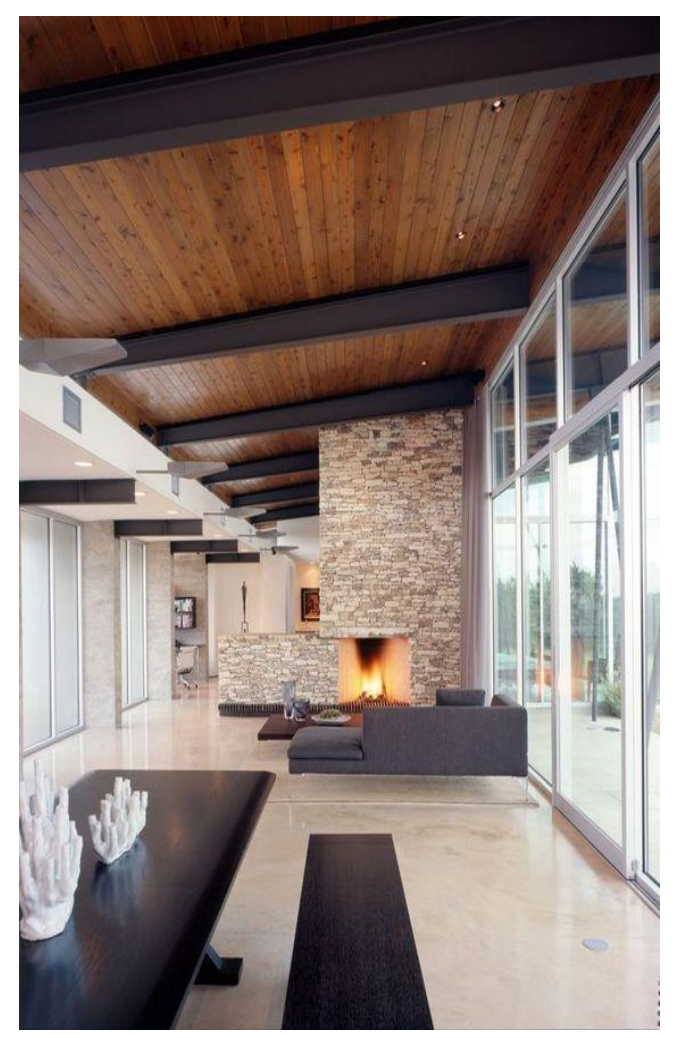

$$
\text { شكل (11 (1) سقلة خشبي حديث مع عو ارضئة }
$$
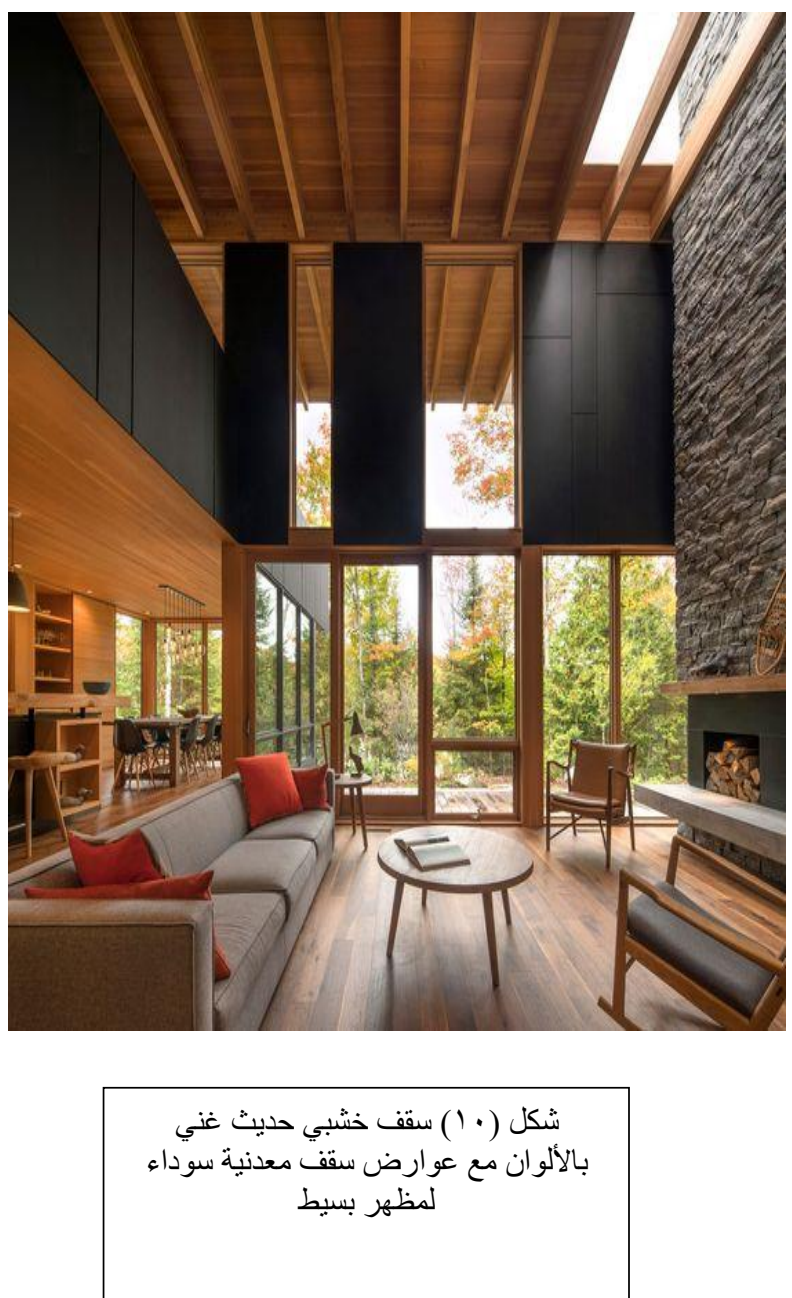

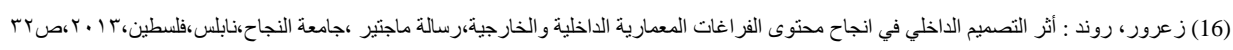
(17) http://finearts.uobabylon.edu.iq/lecture.aspx?fid=13\&lcid=45143 
G. Salem, The Aesthetic Value of Contemporary Ceilings; Vol. 9, R. 2021, Issue No. 1.

\section{1 - الاساليب الجمالية في تصميم الاسقف المعاصرة :-}

ان النظرة الفلسفية المعاصرة عند نقاد ورو اد العمارة والتصميم تؤكد على اهمية الجمال على وفق معطيات النفعية ، باعتبار ان الجمال

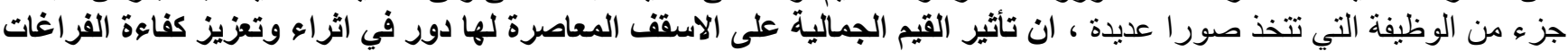
ومن هنا يدرك كل من لديه ادنى اهتمام بالعمارة الداخلية صعوبة انشاء تصميم اصلي منو ازن يجمع بئ بين مجموعة متنو عة من من العناصر

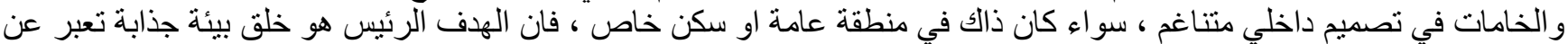

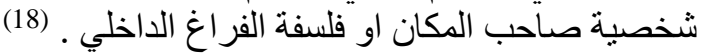

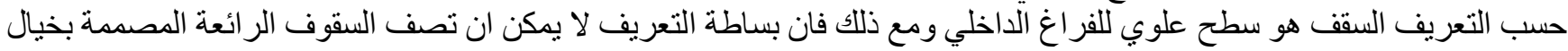

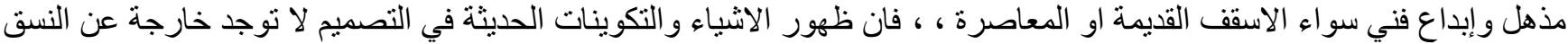
الجمالي و الوظيفي ، حيث نجد معالجات فنية وظيفية بطريقة تطبيقية حرفية ، فأفكار التصميم المعاصرة توفر جاذبية بصرية وجماتية واليات

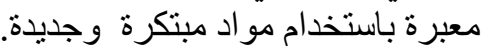

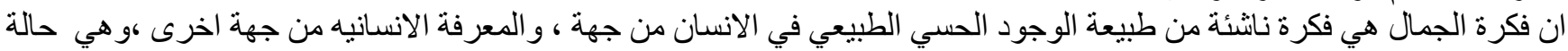

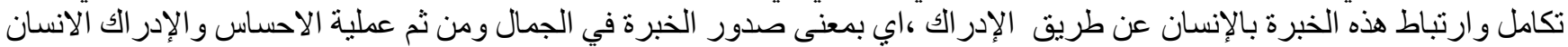
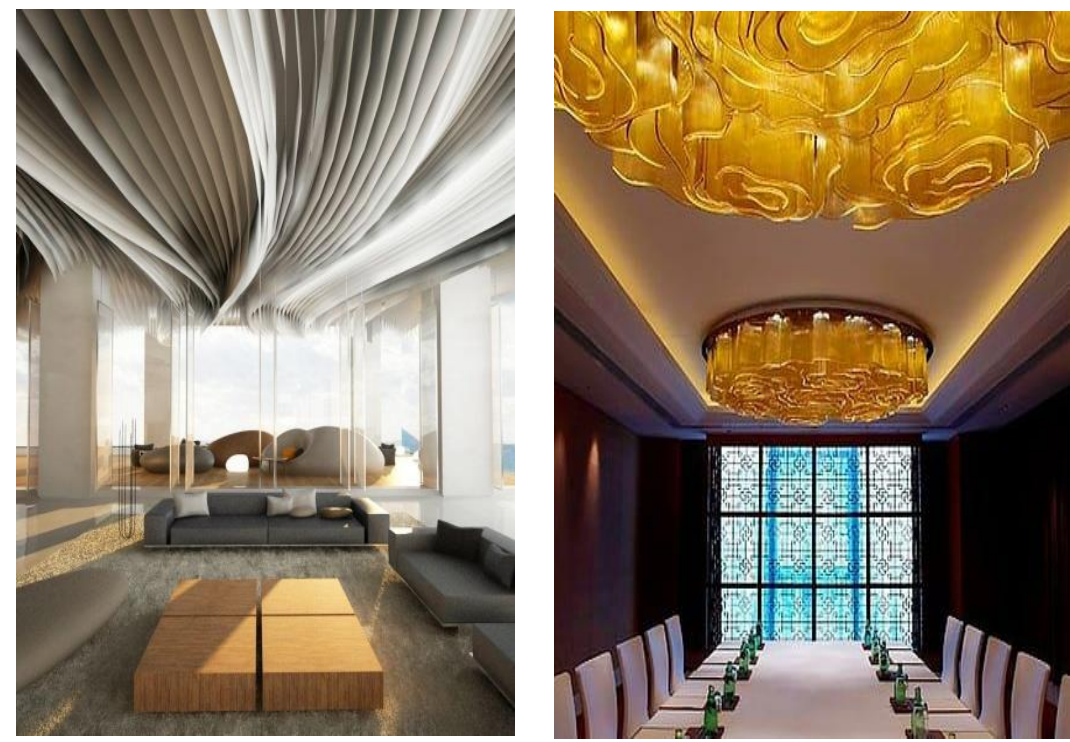

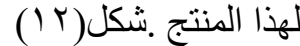

شكل (r ا ) خلق امكانيات التصميم المتنو عة الحديثة لتصميم الاسقف باستخدام المواد المصنعة للبناء لجميع انواع الانثاءات، بتنوع الخامات وترابطها مع عناصر الفر الغ يخلق بيئة مريحة للمستخدم.

و اذا تم ارتباط هذه الفكرة مشاهدة مصدر اثارة الجمال بوجود الاسقف في فر اغات داخلية تحمل ذات قمية ومعاني جمالية يمكن

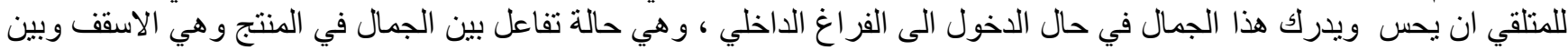

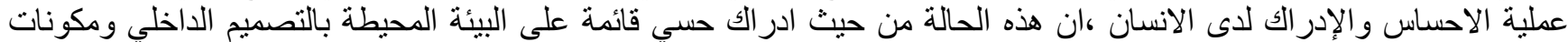

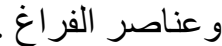

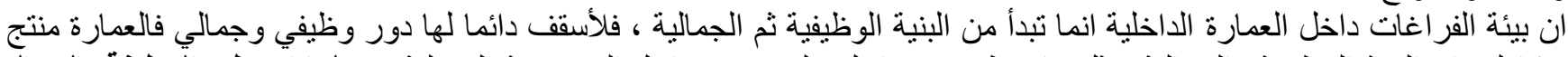

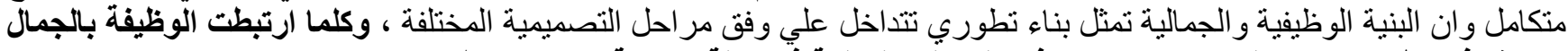

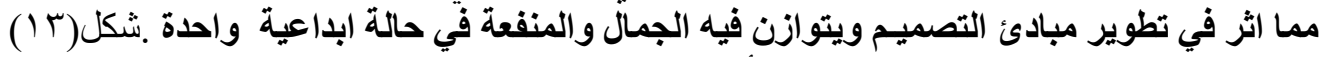

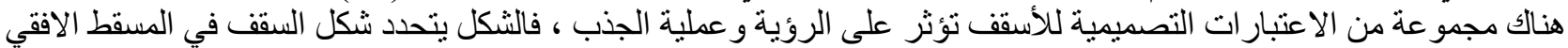

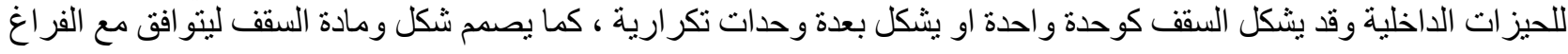

(18)https://deavita.net/amazing-ceiling-design-ideas-make-real-statement.html 


\section{SJFA}

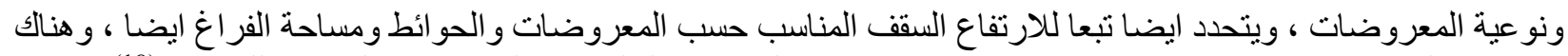

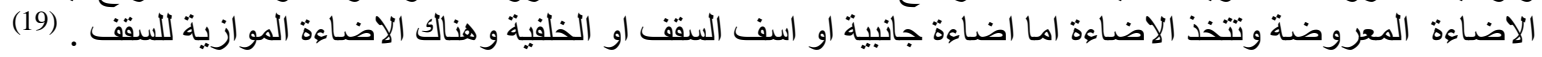
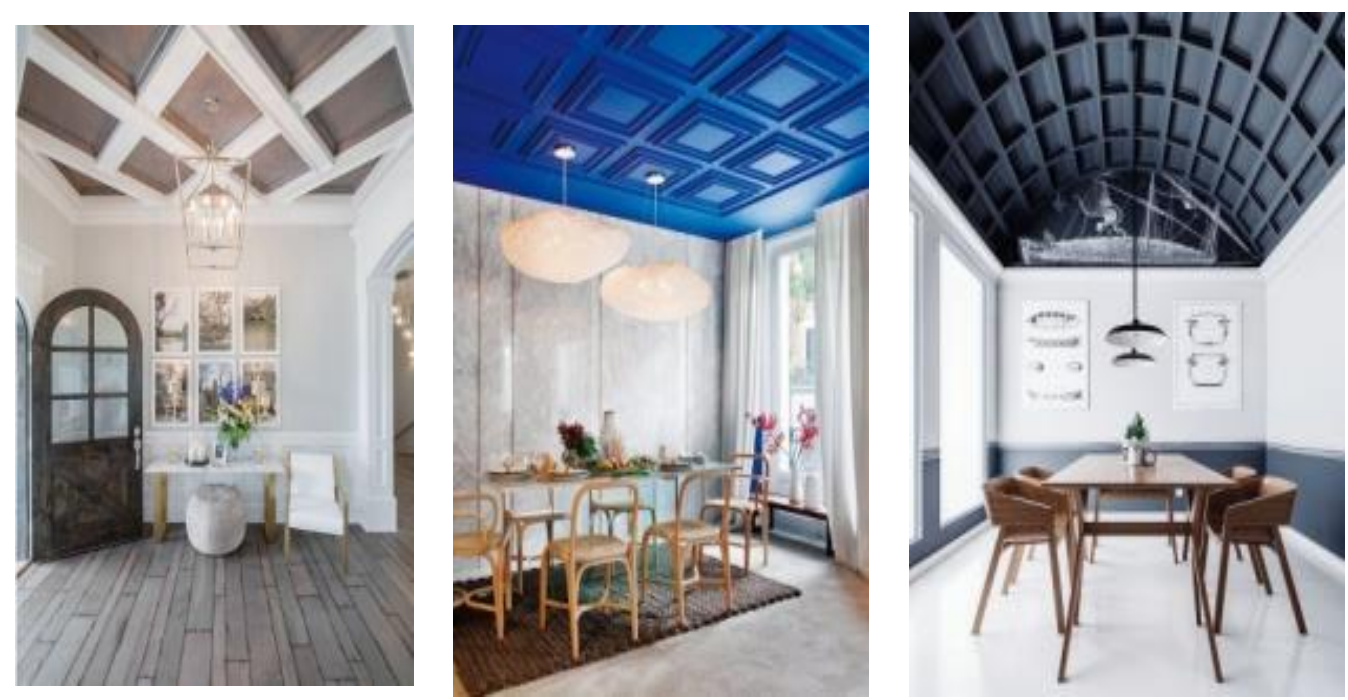

شكل (r 1 (1)يضيف السقف ذو التجاويف البني و الأبيض بلون الثوكو لاتة لمسة راقية و أنيقة إلى الدذخل

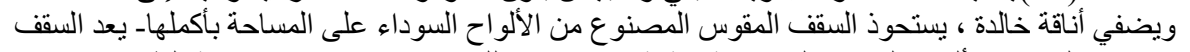
المكسو بالألو اح الزرقاء الكهربائية بمثابة بيان رئيسي اللون وميزة تصميم في غرفة الطعام. الطئ.

و عليه فان القيمة الجمالية للأسقف في بيئة العمارة الداخلية تحدد نوع العلاقة بين الانسان وبيئته ، وارتباط الاسقف مع القيمة الجمالية

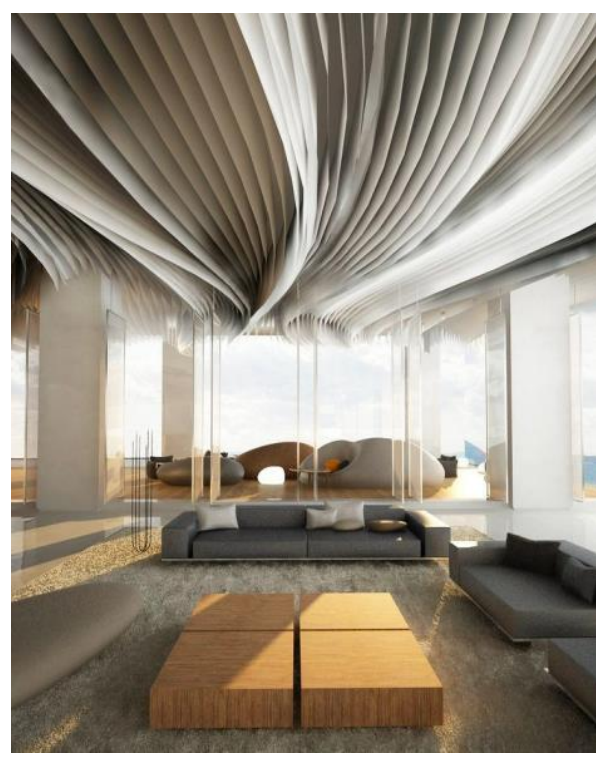

شكل (ع ()بعيدا عن الاسقف البيضاء أسقف

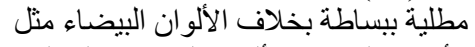
الأسقف المزينة بالألو اح الخشبية والقوان البناء

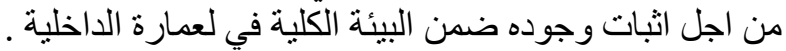

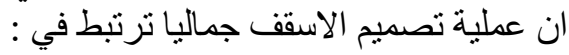

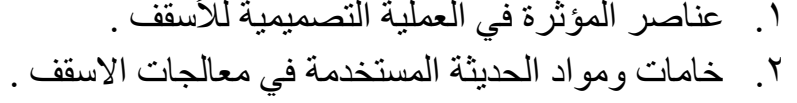

11 ــ بعض عناصر المؤثرة في العملية التصميمية للأسقف :-(اللون ـالاضاءة )

عند تصميم الاسقف في الفراغات الداخلية يجب تحقيق التوازن و التزاوج ين القيم

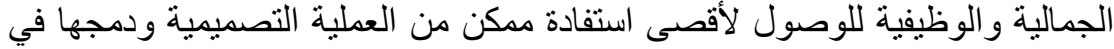

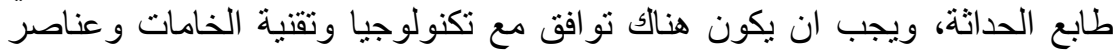

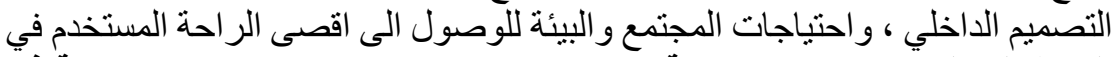

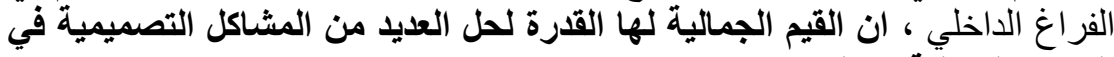

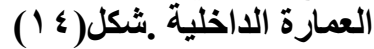

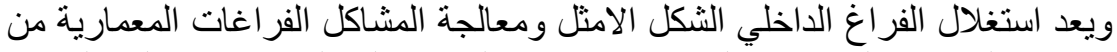

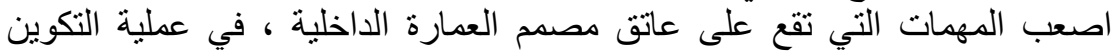

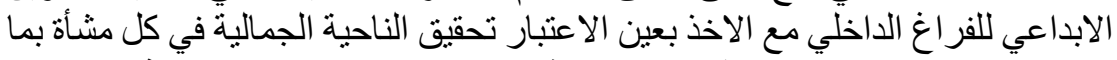

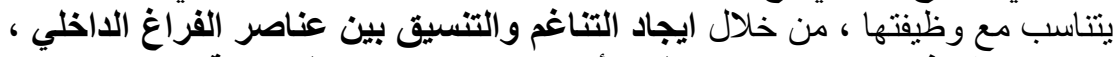

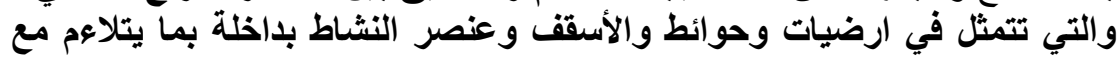
الغرض الوظيفي والقناعة السيكولوجية ضمن التئ التصاميم

الاخلية . (20)

(19)https://maut.journals.ekb.eg/article_104756_5f41effc0a5eeefe5552ebaee8e354c4.pdf

(20) خوري ، جريس (9 . . ץ) : " التصميم الداخلي " ، دار قابس للطباعة والنشر، الطبعة الأولى ، لبنان .ص؟ب 
G. Salem, The Aesthetic Value of Contemporary Ceilings; Vol. 9, R. 2021, Issue No. 1.
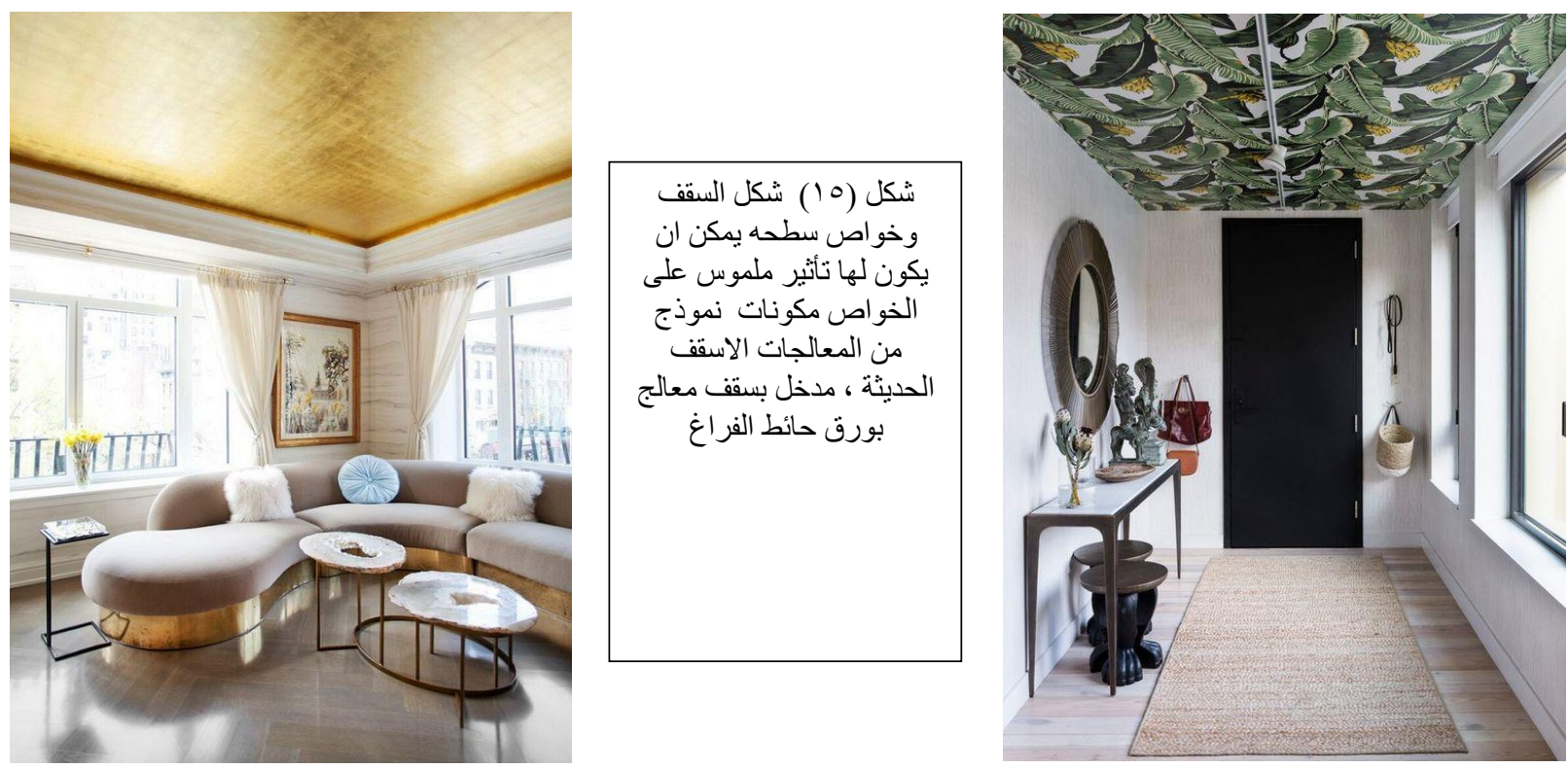

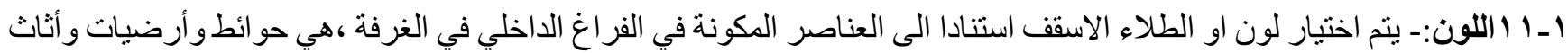

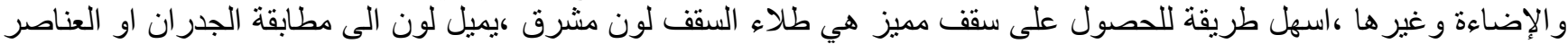

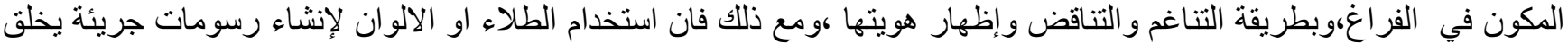

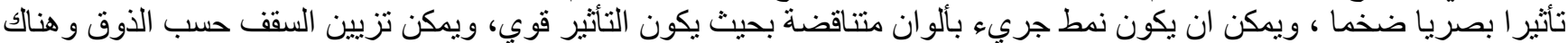

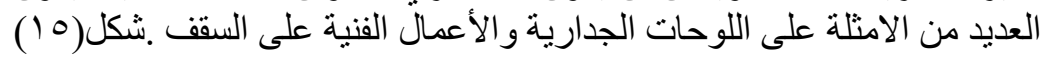

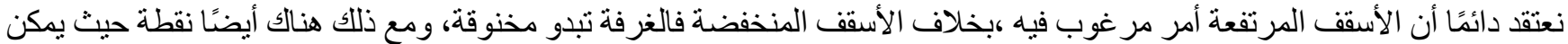
أن تجعل الأسقف العالية جدًا المساحة تبدو كبيرة جدًا ومخيفة، هذا هو المكان التِان الذي يمكنك فيه استخدام اللون الداكن لجعل المظهر كله

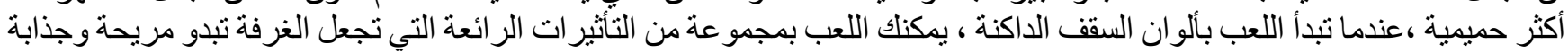

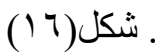

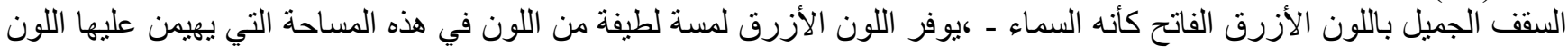

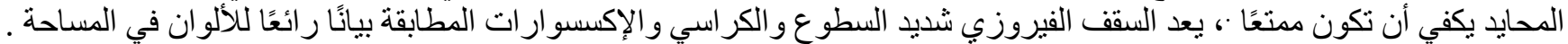

شكل(iv)

العناصر المعمارية من جدران وأسقف وأرضيات لاز الت من اهم المؤثرات على اتجاه التصميم المعماري من حيث الانماط الملائمة

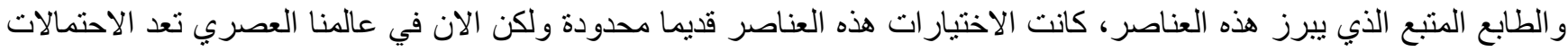

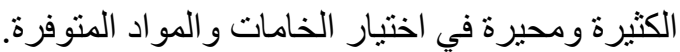

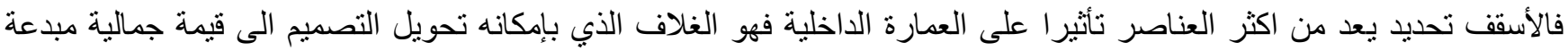

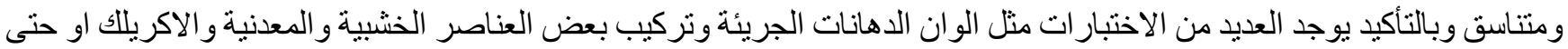

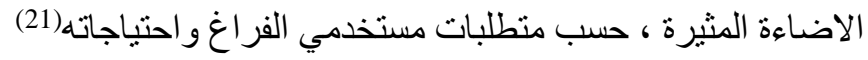

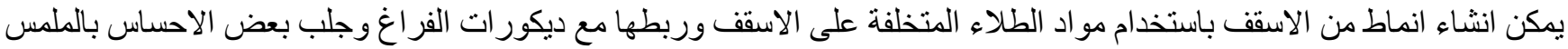

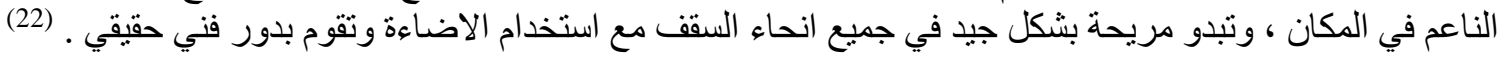

(21) https://www.homify.ae/ideabooks/1238180/10-فكار-مبتكرة_لتصاميم-الاسقق

(22) https://mindfuldesignconsulting.com/gallery/ 


\section{SJFA}
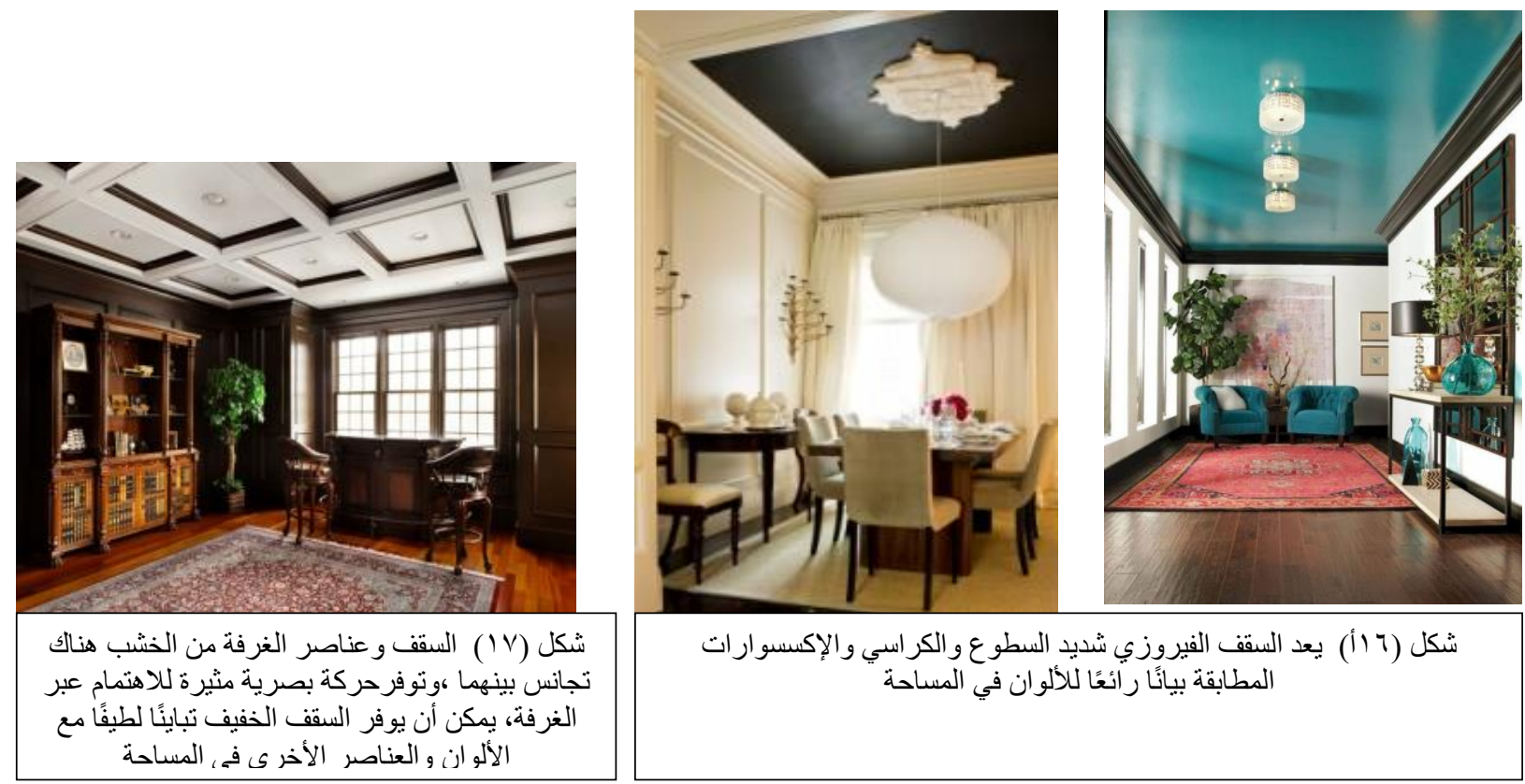

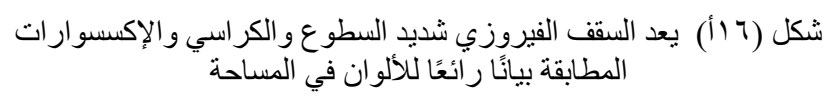

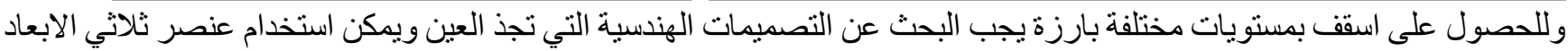

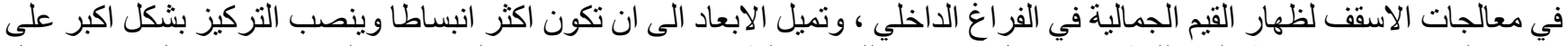

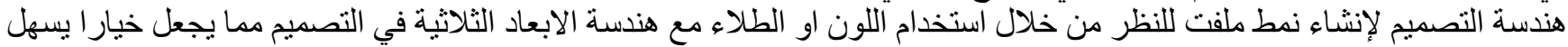

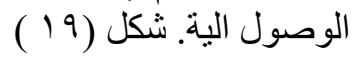
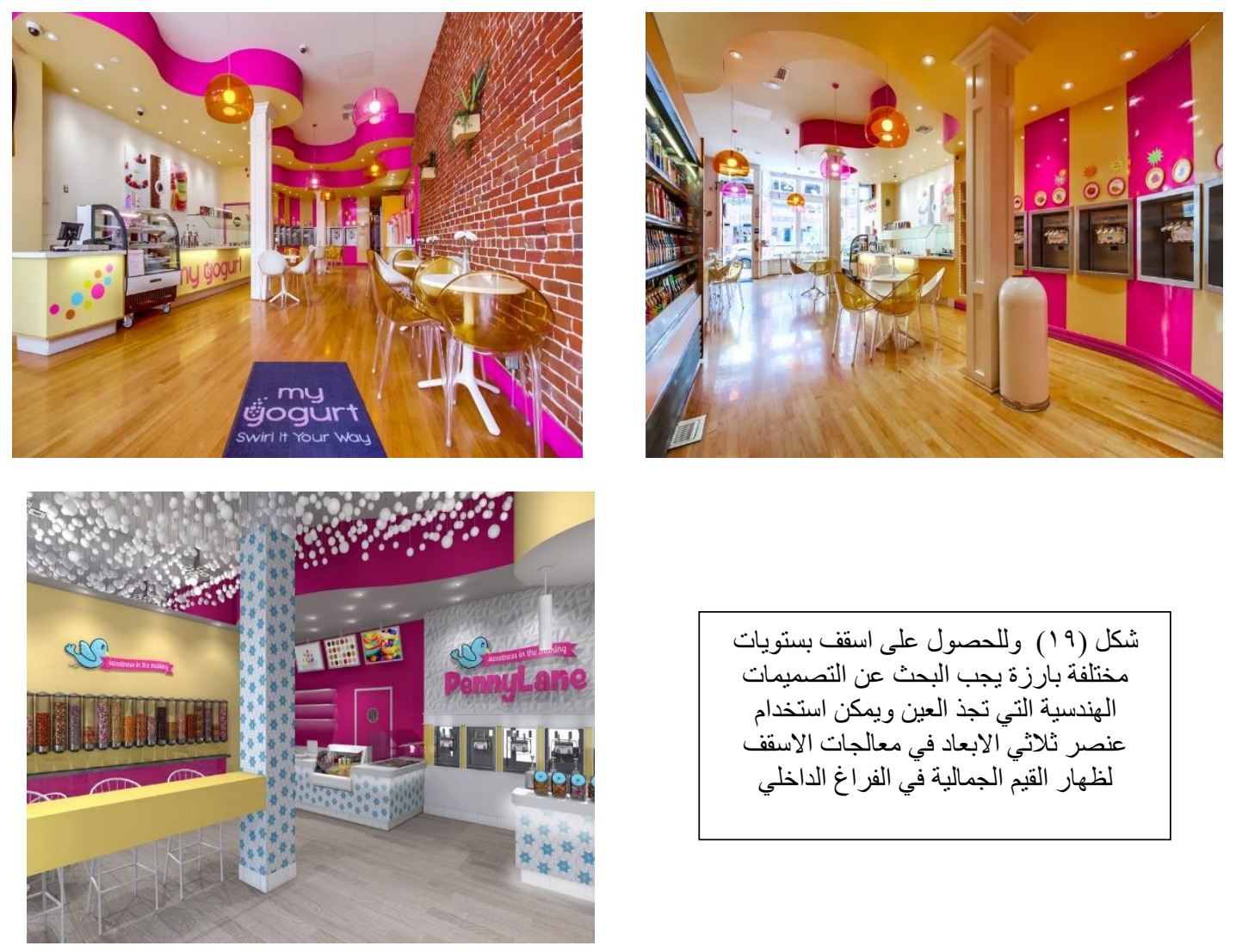


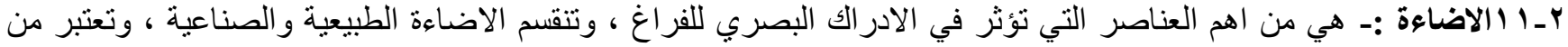

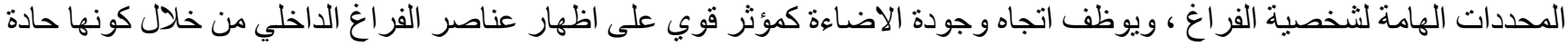

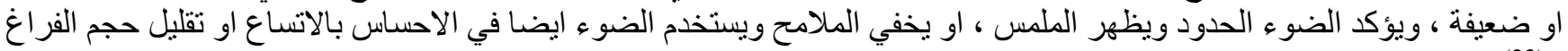

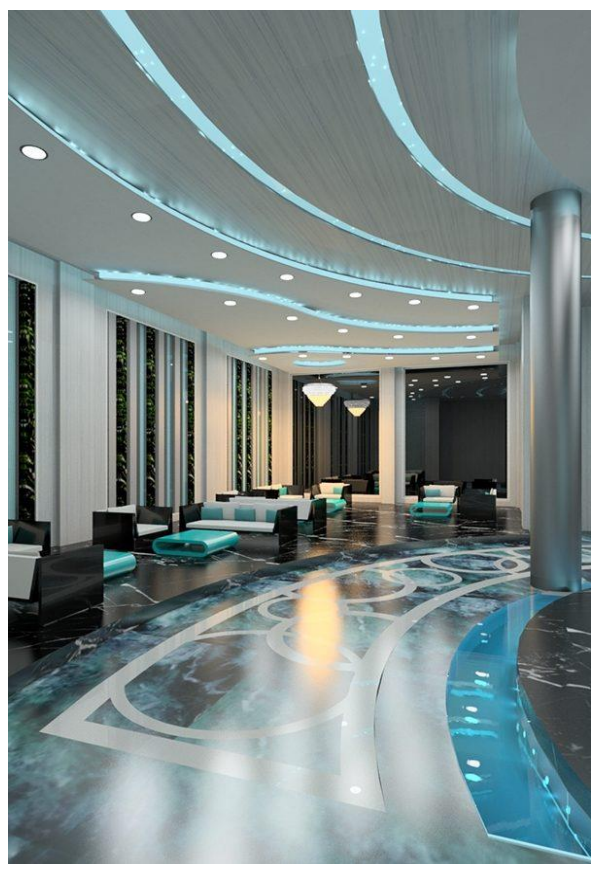

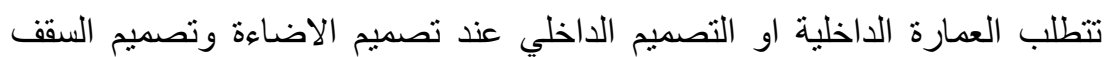

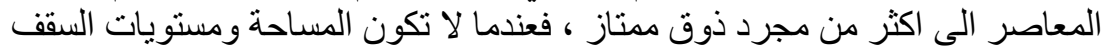

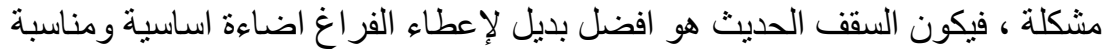

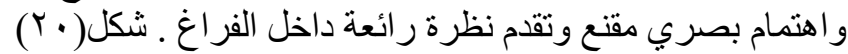

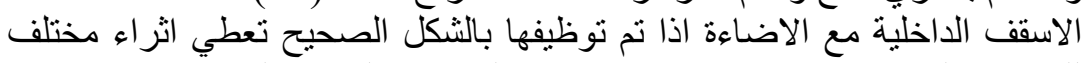

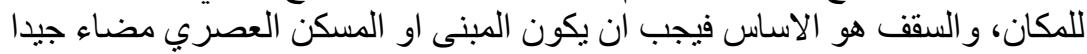

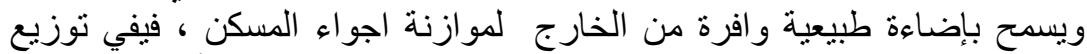

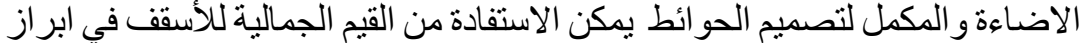

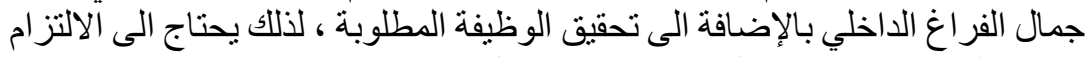

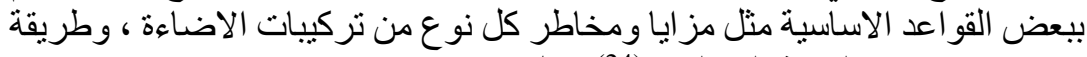

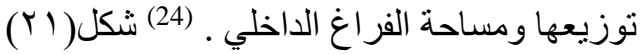

$$
\text { شؤثر في (r) هي من الادر الهم العناصر اللفي التي }
$$
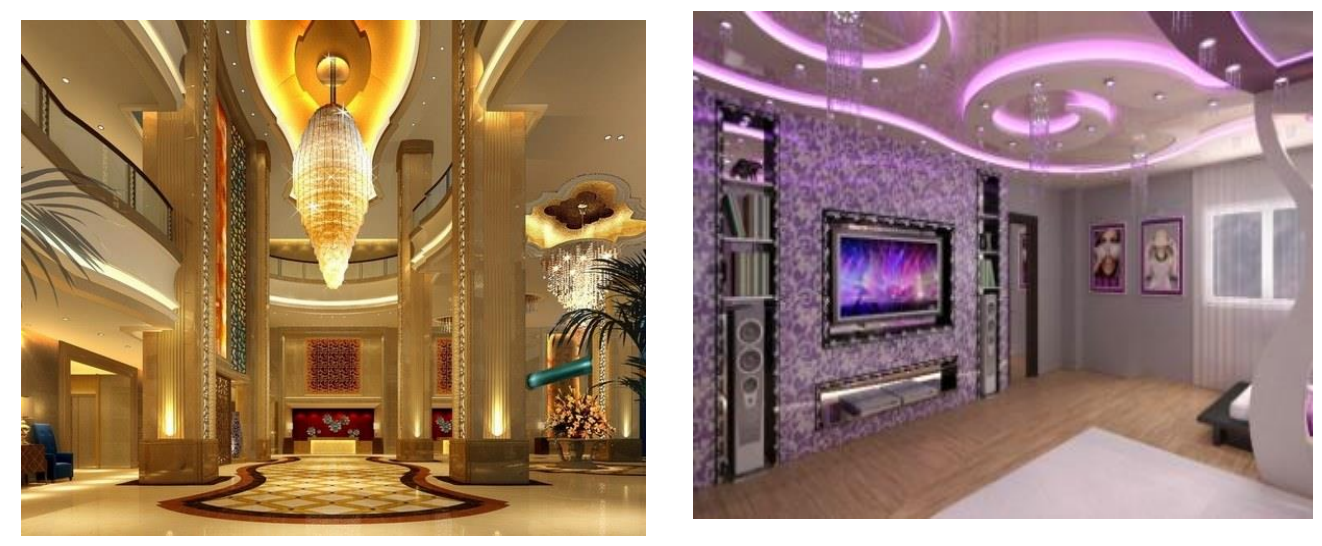

شكل (Y) يستخدم الضوء ايضا في الاحساس بالاتساع او تقليل حجم الفراغ

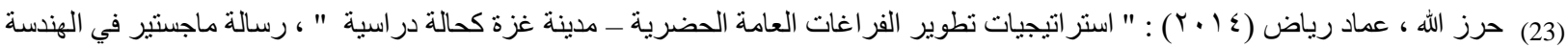

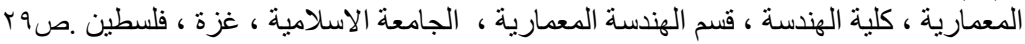
(24) https://deavita.net/amazing-ceiling-design-ideas-make-real-statement.html 


\section{SJFA}
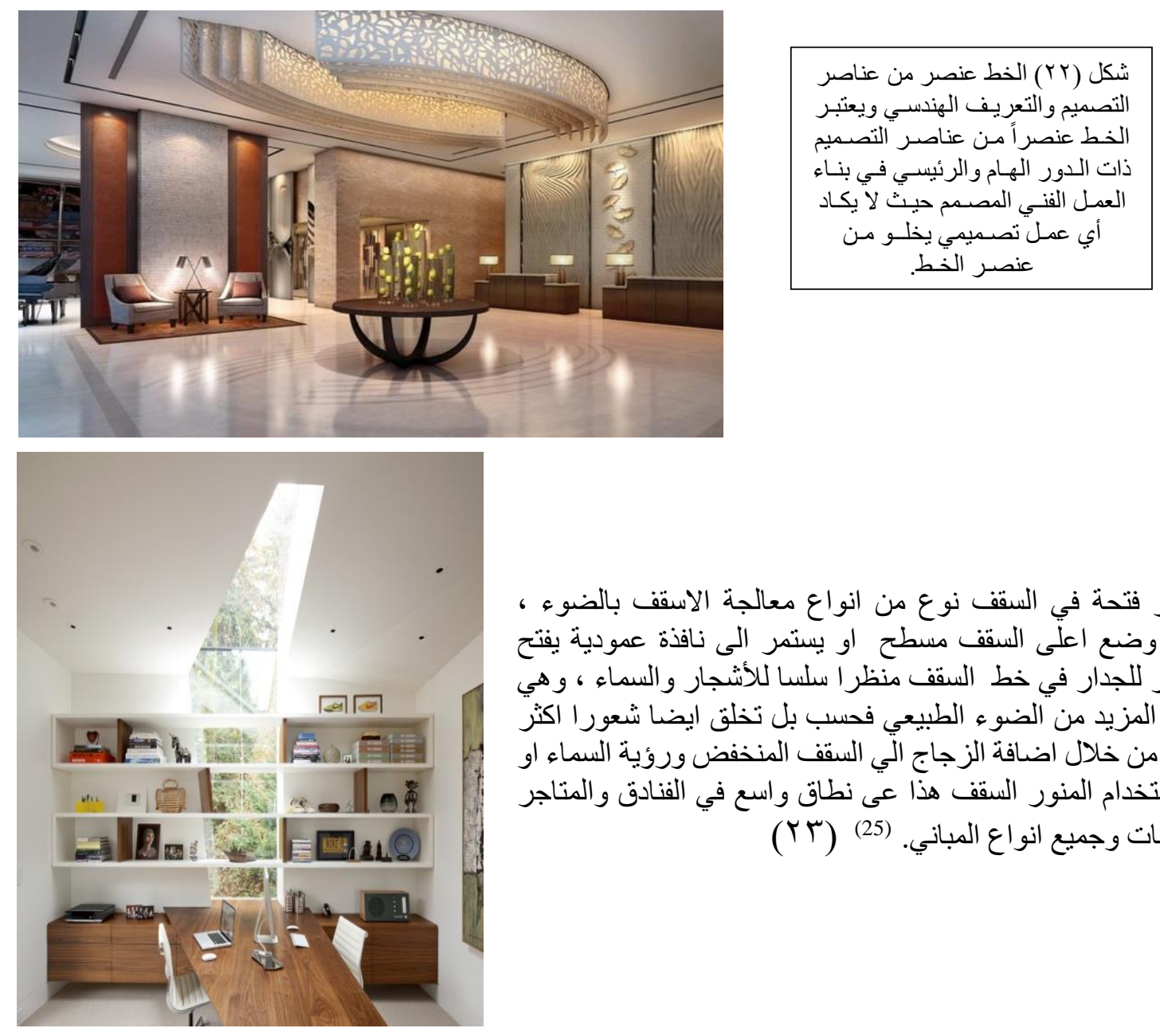

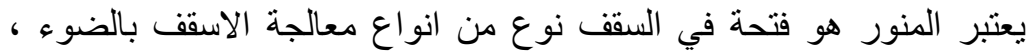

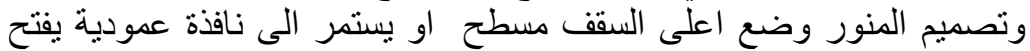

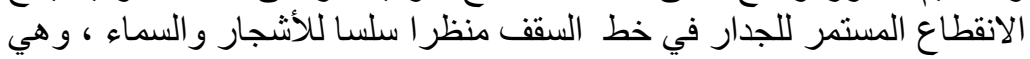

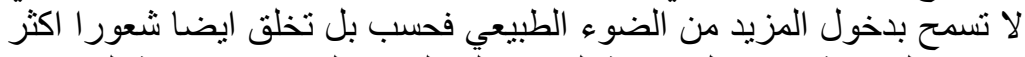

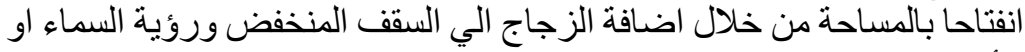

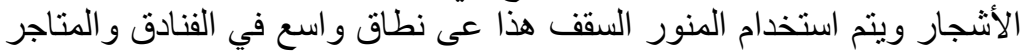

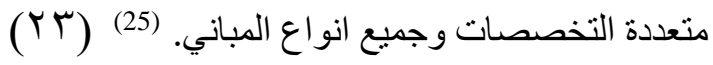
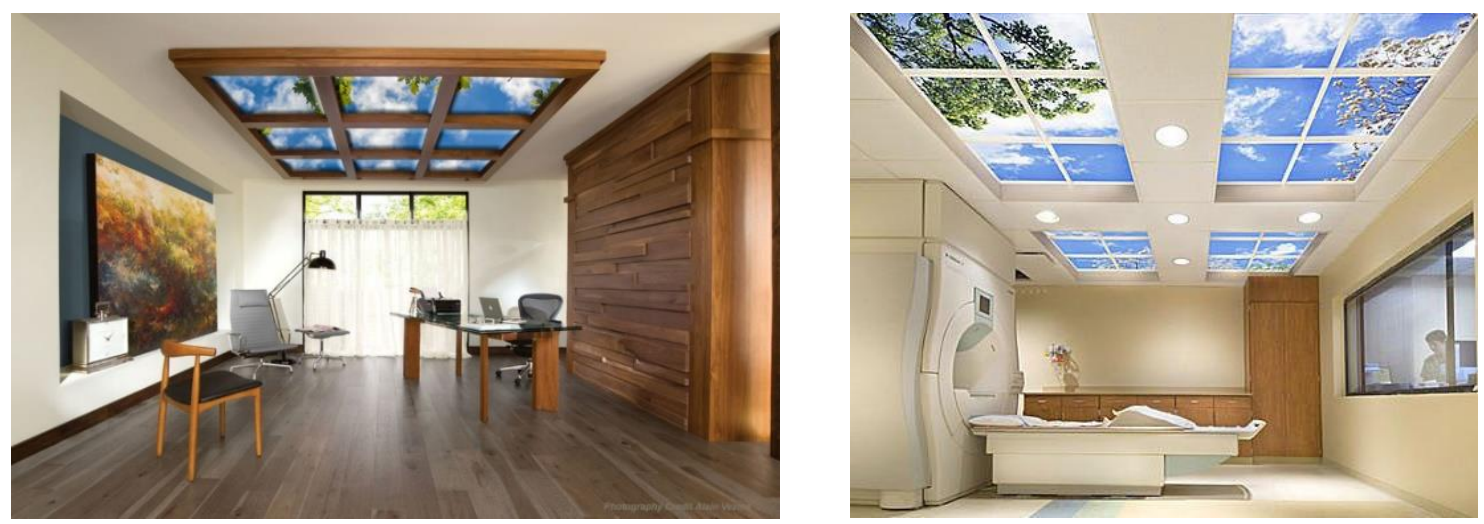

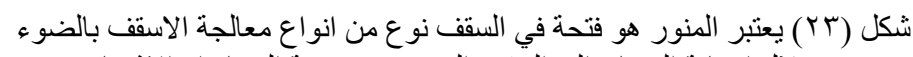

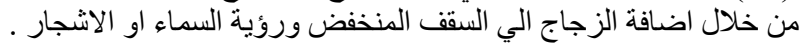


G. Salem, The Aesthetic Value of Contemporary Ceilings; Vol. 9, R. 2021, Issue No. 1.
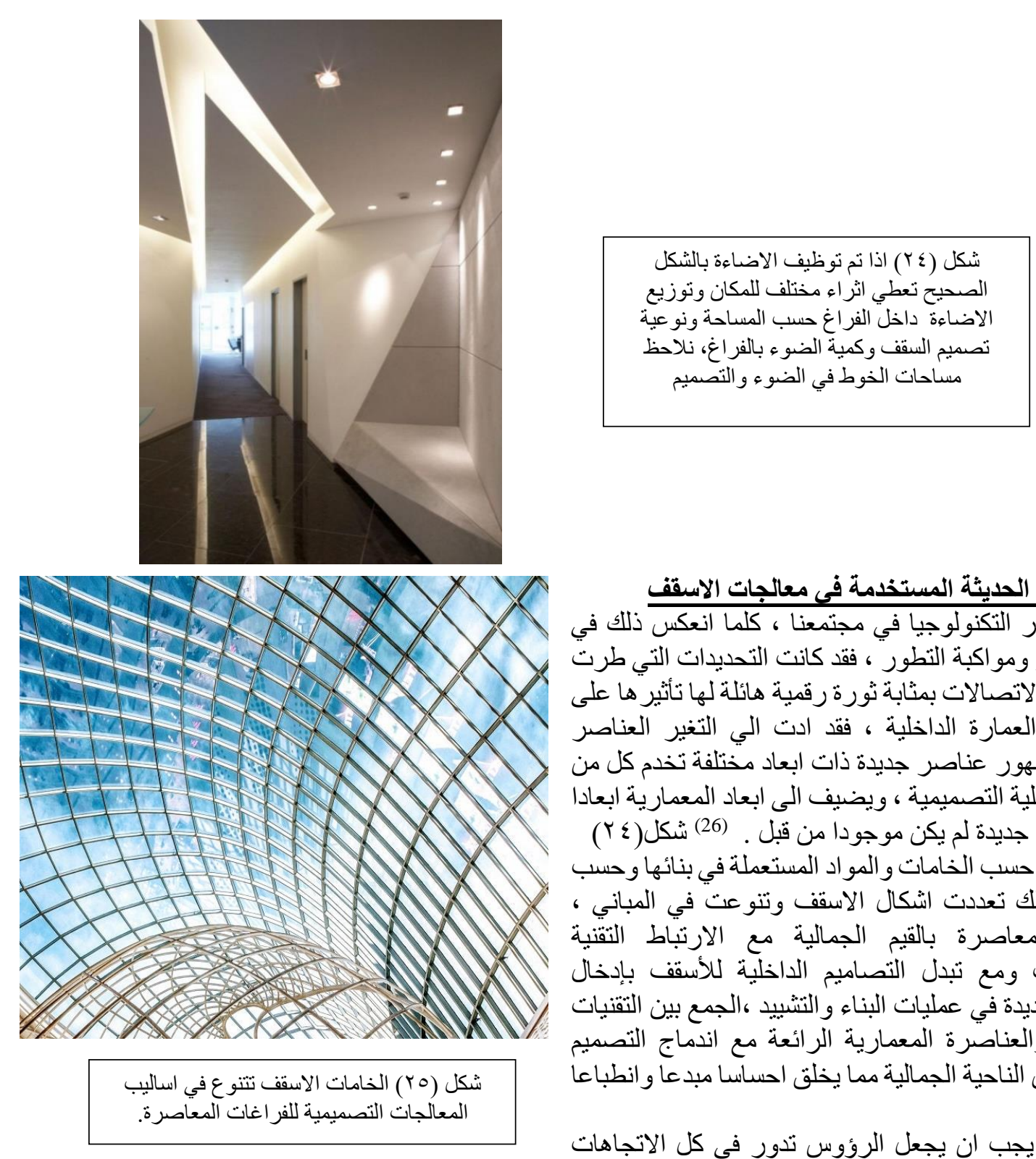

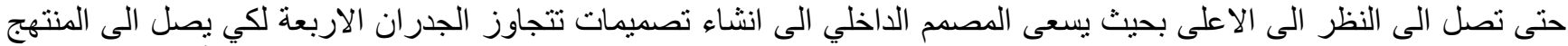

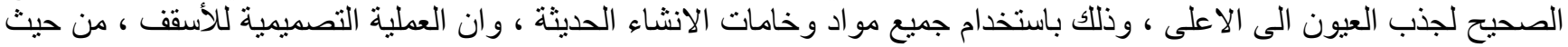

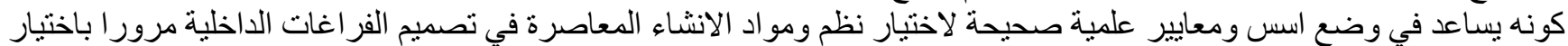

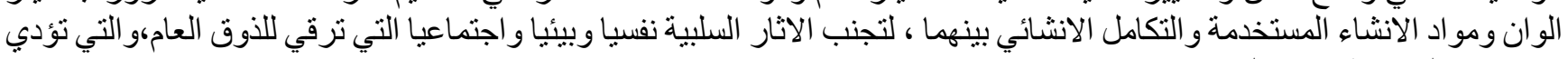

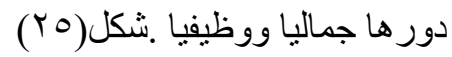




\section{SJFA}

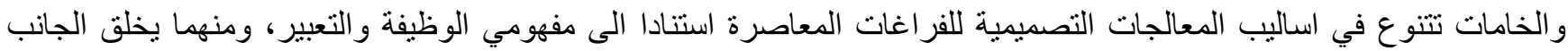

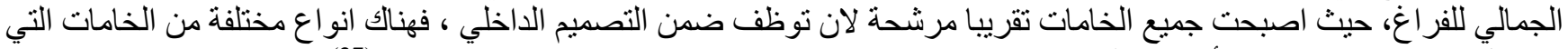

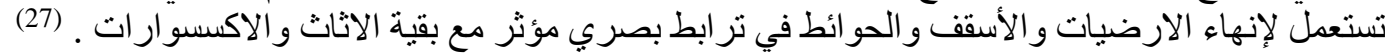

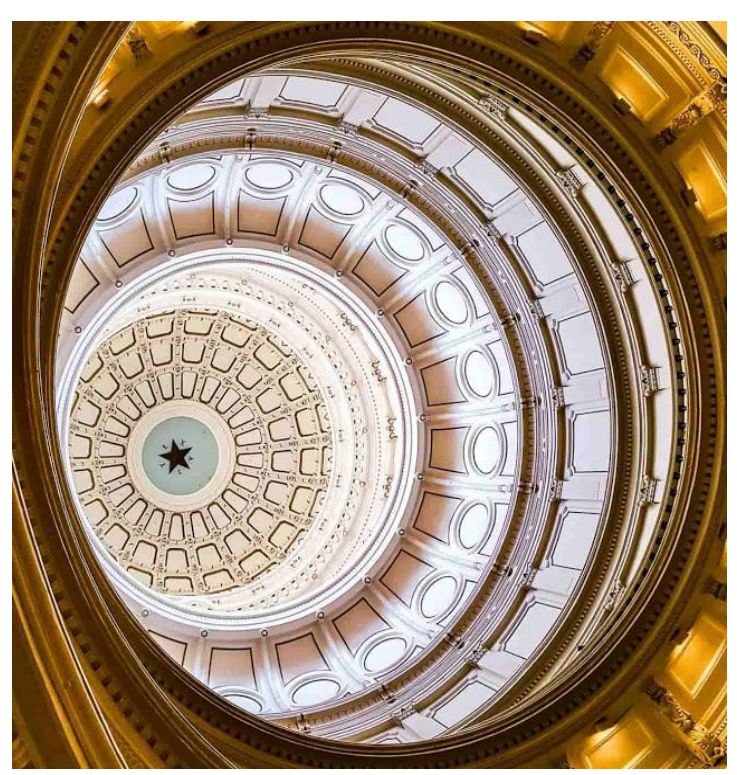

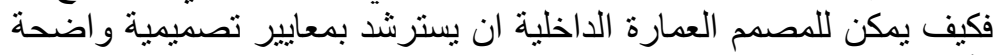

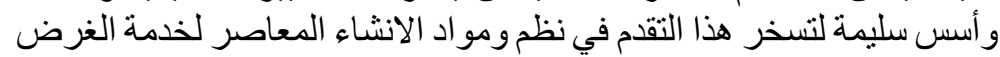

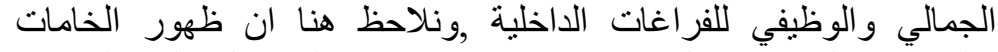

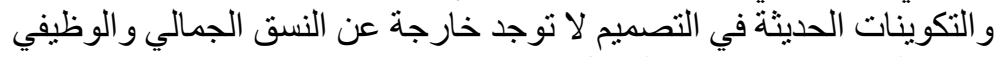

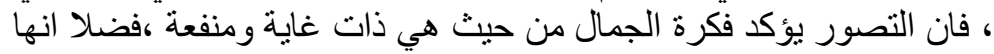

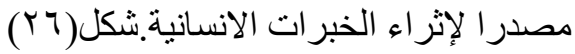

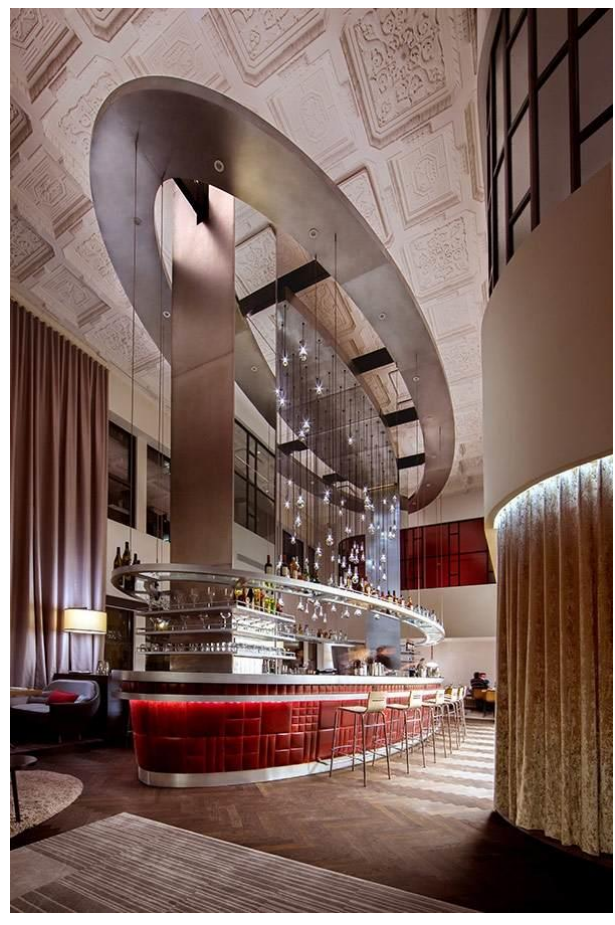

ويعتبر الادر الك الواسع لعناصر والتصميمية والمعمارية وتفاصيلها من اساسيات

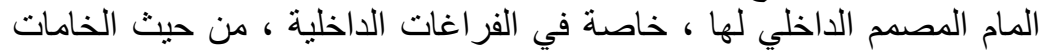

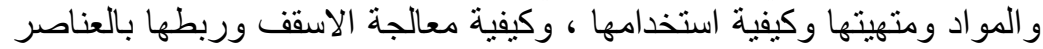

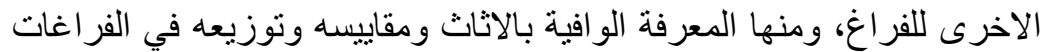

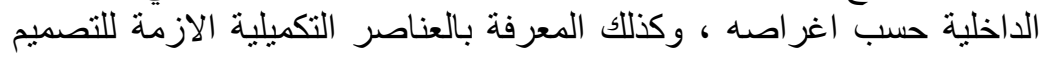

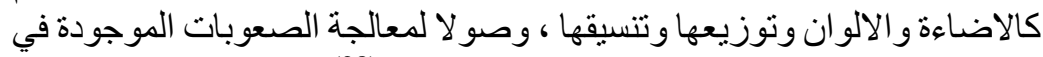
الفراغ كافة ، وجعله مريحا ممتعا بهيجا للمستخدم . (28) شكل (YV)

شكل (rV) التغير العناصر المعمارية التقليدية وظهور عناصر جديدة ذات ابعاد مختلفة تخدم كل العند

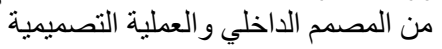

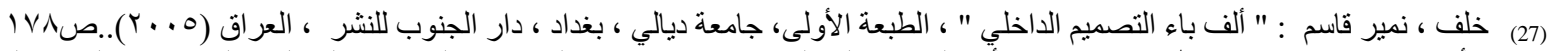

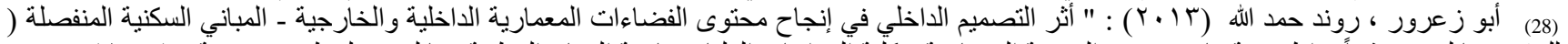
الفلل ) في نابلس نموذجاً " اطروحة ماجستير في الهندسة المعمارية ، كلية الدراسات العليا ، جامعة النجاح الوطنية ، نابلس ، فلسطين ، صفحة 10 ـ 17 
G. Salem, The Aesthetic Value of Contemporary Ceilings; Vol. 9, R. 2021, Issue No. 1.

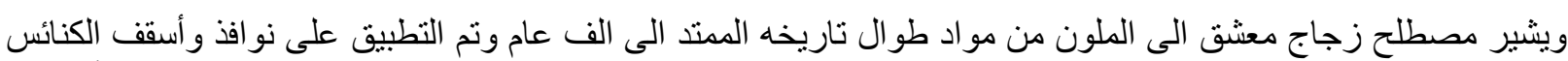

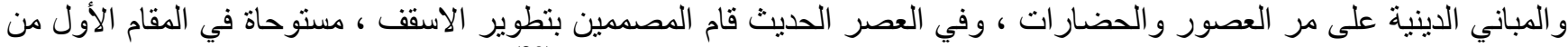

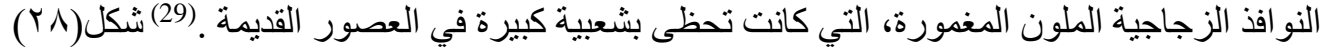

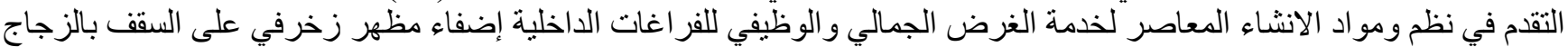

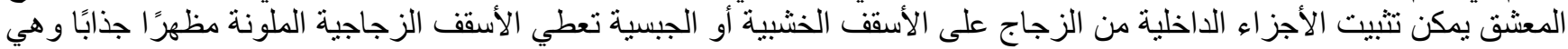

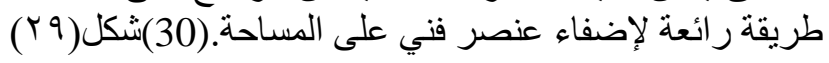
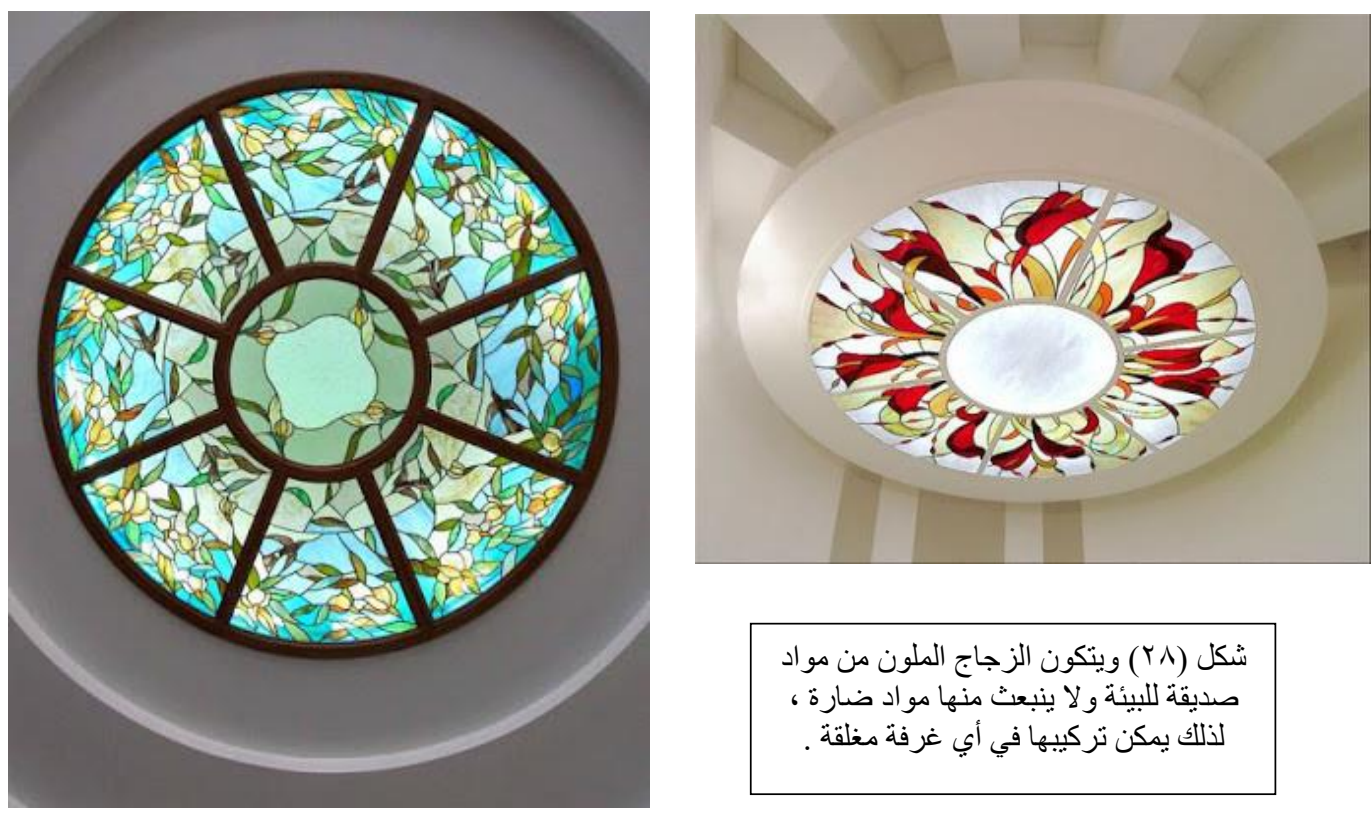

شكل (Y^) ويتكون الزجاج الملون من مو اد

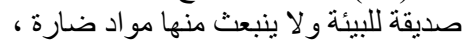

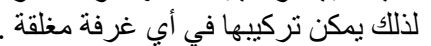
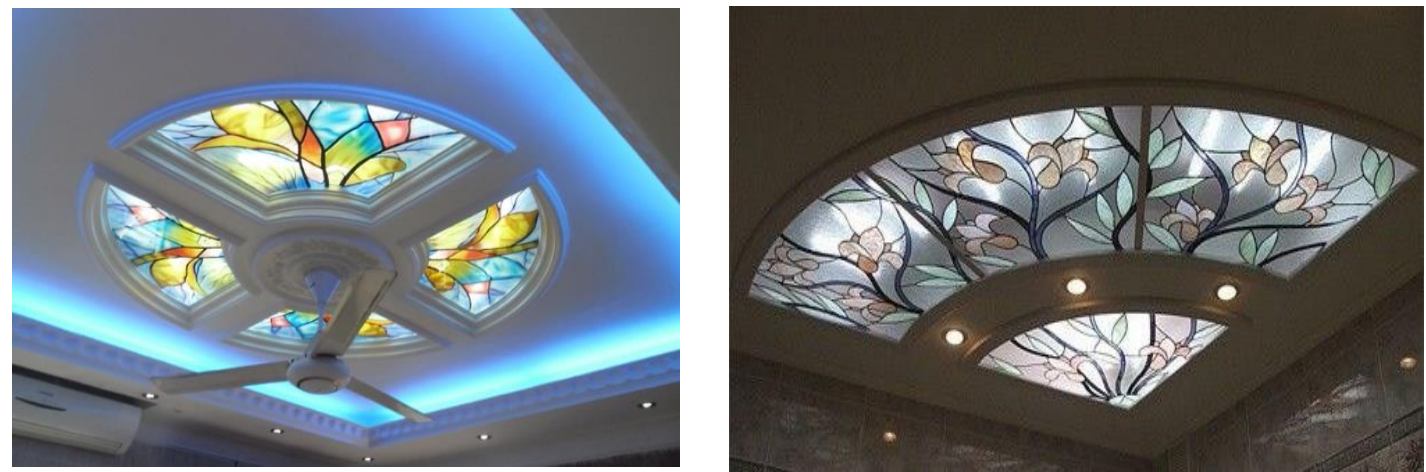

شكل (Yq) السقوف الزجاجية الملون هي هياكل معلقة ، تتكون من إطار

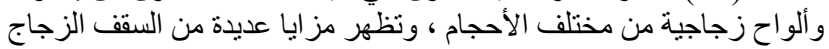

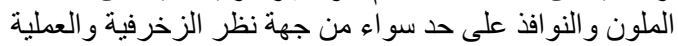




\section{SJFA}

ا. . استطاع مصمم العمارة الداخلية الالمام بالقيم الجمالية في الفر اغ الداخلي من خلال الاهتمام بالعناصر ومكونات التصميم في اطار

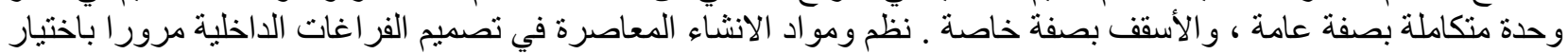

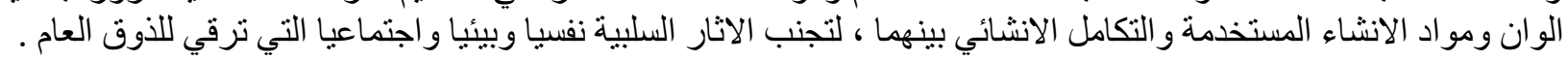

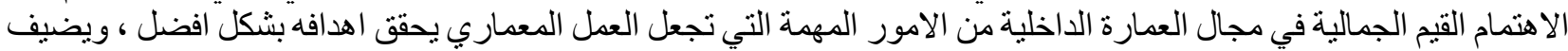

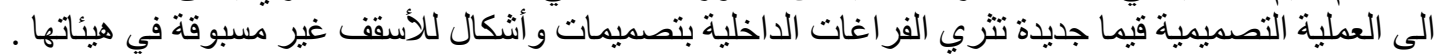

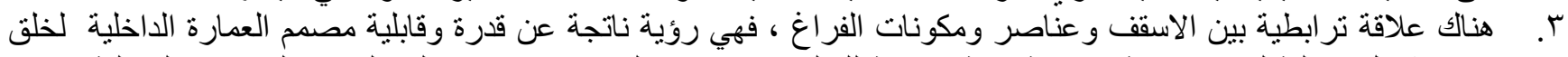

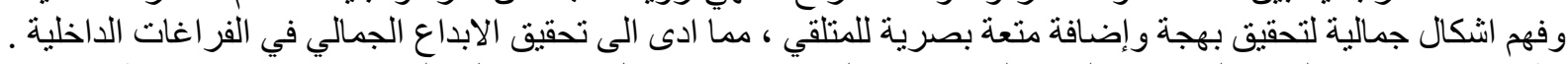

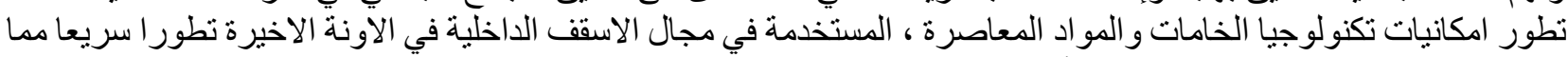

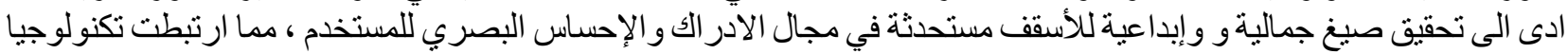

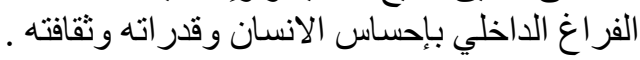

التوصيات:

ا. . يوصي البحث بضرورة التأكيد على اهمية وفهم ودر اسة المصمم الداخلي في العلاقة بين مكونات المؤثر في عناصر الفراغ الداخلي

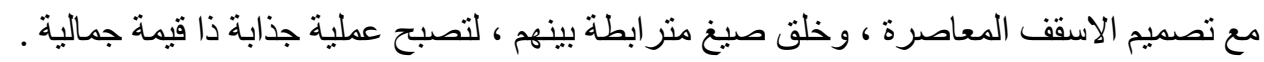

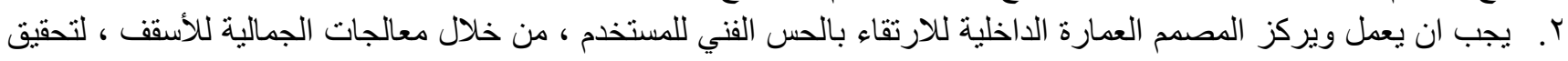

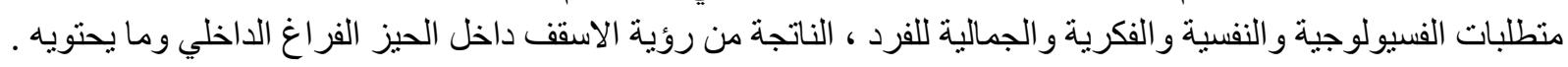

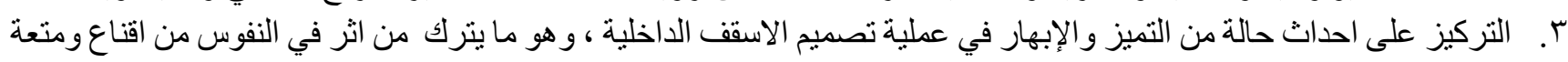

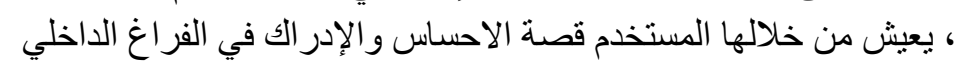

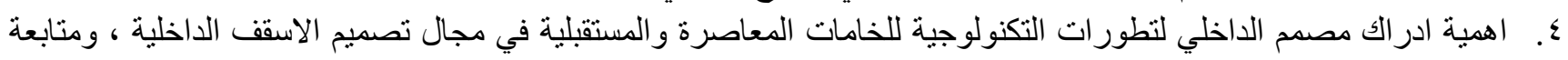

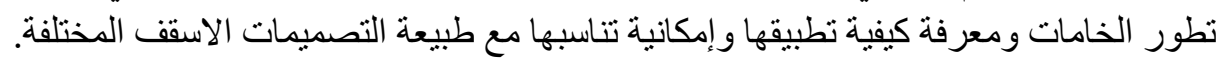

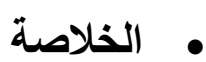

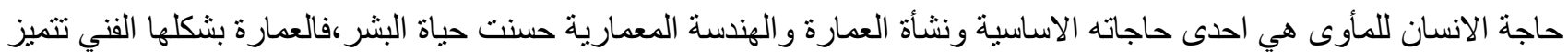

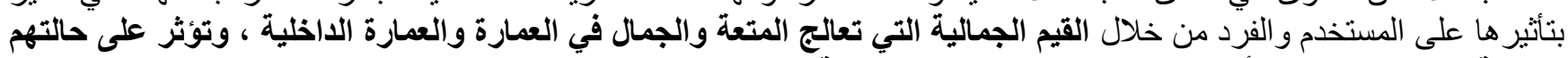

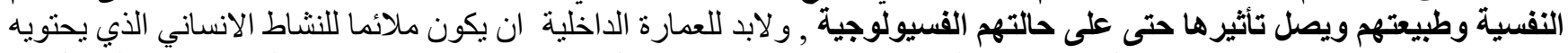

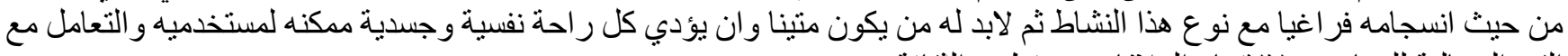

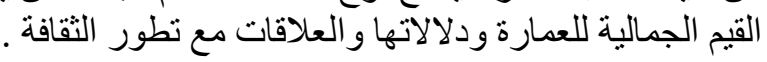

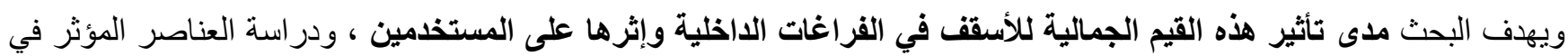

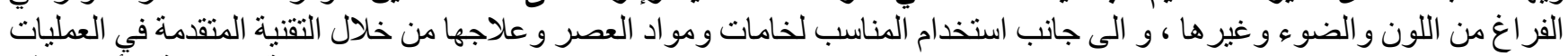

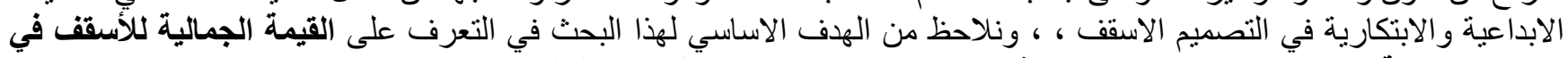

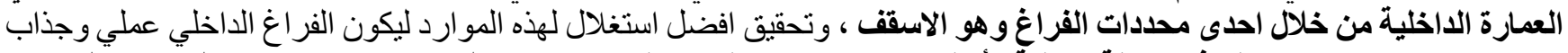

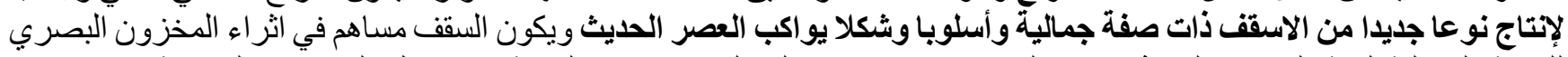

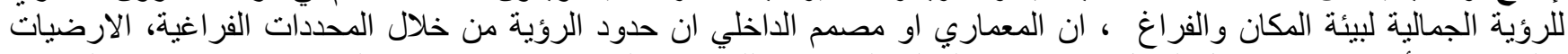

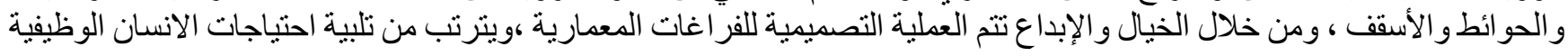


G. Salem, The Aesthetic Value of Contemporary Ceilings; Vol. 9, R. 2021, Issue No. 1.

و الجمالية والنفسية، مما يزيد المتعة بالحياة الانسانية ويثير ها بتجارب فر اغية مثتوعة مشحونة بالانفعالات والمشاعر حيث ان الحيز

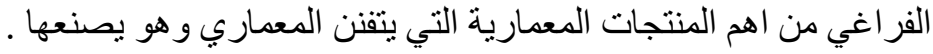

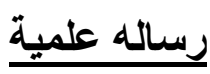

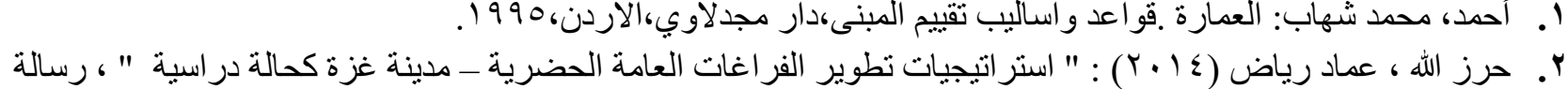

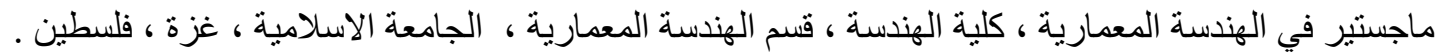

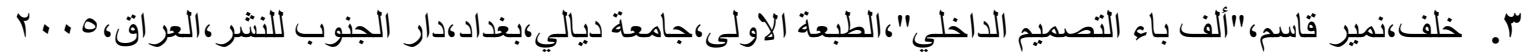

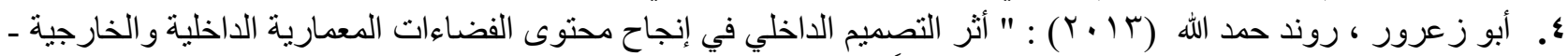

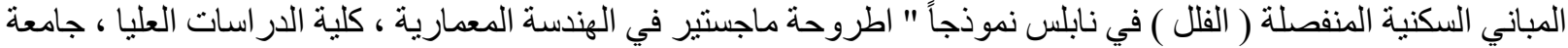

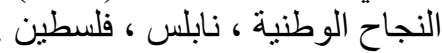

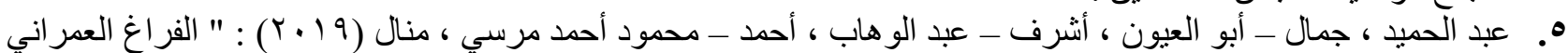

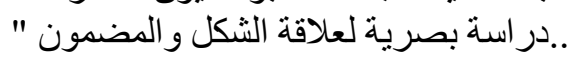

1- https://arabicpost.net/تعريف القيم/Wiki

r-https://ar.wikipedia.org/wiki/ تعريف فلسفة الجمال

3 - https://oktamam.com/العمارة-و العمارة الداخلية/2hec

4- Ashihar.Yoshinobu-'Exterior Design In Architecture'-Van Nostrand Reinhold.NEW York..1981,P(14)

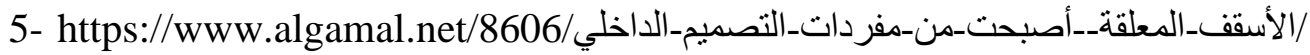

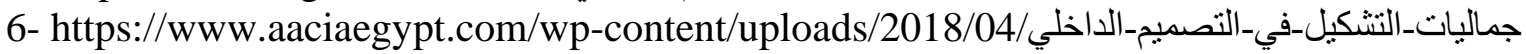

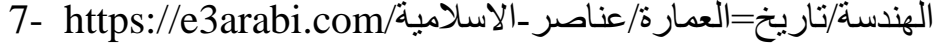

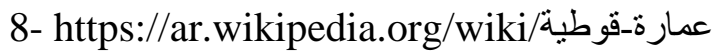

9- / https://ar.wikipedia.org/wiki العمارة البيزنطية

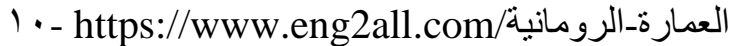

$11 \mathrm{http}: / /$ finearts.uobabylon.edu.iq/lecture.aspx?fid=13\&lcid=45143

12- https://deavita.net/amazing-ceiling-design-ideas-make-real-statement.html

13https://maut.journals.ekb.eg/article_104756_5f41effc0a5eeefe5552ebaee8e354c4.pdf

14- https://www.homify.ae/ideabooks/1238180/10-فكار-مبتكرة-لتصاميم-الاسقق

15- https://mindfuldesignconsulting.com/gallery/

16- https://deavita.net/amazing-ceiling-design-ideas-make-real-statement.html

17- http://www.home-designing.com/modern-residential-indoor-skylight-design-ideas

1^- https://www.homify.com.eg/

19- https://www.houzz.in/photos/installing-stained-glass-panels-in-false-ceiling-designs-phvw-

vp 115340026 


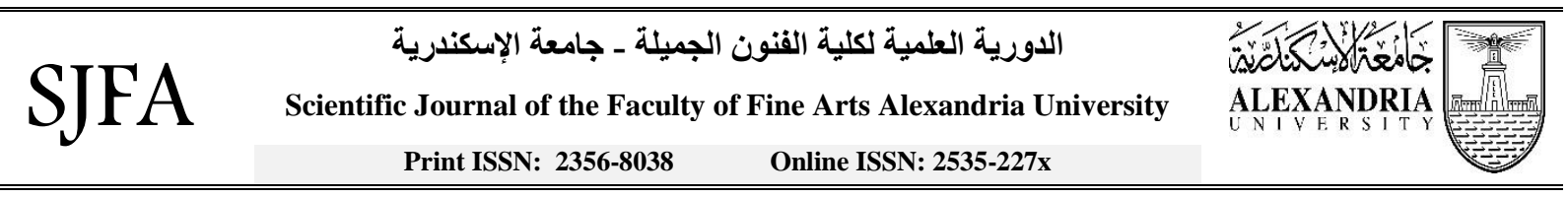

\title{
The Aesthetic Value of Contemporary Ceilings
}

\author{
G. Salem ${ }^{31}$
}

\section{ABSTRACT}

The human need for shelter is one of his basic needs, and the emergence of architecture has improved human life. Architecture in its artistic form is distinguished by its effect on the user and the individual through aesthetic values that address the pleasure and beauty in architecture and interior architecture, and affect their psychological state and nature and it affects even their physiological state, The interior architecture must be appropriate to the human activity it contains in terms of its spatial harmony with the type of such activity, then it must be solid and perform all possible psychological and physical comfort for its users and deal with the aesthetic values of architecture and its connotations and relations with the development of culture. The research aims to find out the extent of the impact of these aesthetic values of the ceilings in the internal spaces and their effect on the users, and to study the elements affecting the space of color, light and others, in addition to the appropriate use of the fabrics and materials of the age and treatment through advanced technology in the creative and innovative processes in the design of ceilings. The main basis for this research is to identify the aesthetic value of ceilings in interior architecture through one of the determinants of space, which is the ceiling and to make the best use of these resources so that the internal space is practical and attractive to produce a new type of ceiling with an aesthetic character, style and shape that keeps pace with the modern era, hence; the ceiling contributes to enriching the visual impact. For the aesthetic vision of the environment of the place and the space, the architect or interior designer can see the boundaries of the vision through spatial determinants, floors, walls and ceilings, and through imagination and creativity the design process of architectural spaces takes place, and it follows from meeting the functional, aesthetic and psychological needs of man, which increases the enjoyment of human life and raises it with spatial experiences. The space is one of the most important architectural products that an architect masters and creates.

KEYWORDS: Format, Introduction, fonts, headings, figures, equations.

31 Ministry of Education - Kuwait

kuwait_art@hotmail.com 